\title{
EFFECT OF TRACE MINERAL SUPPLEMENTATION ON GASTRIC ULCERS IN EXERCISING YEARLING HORSES
}

\author{
A Thesis \\ by \\ ALEXA DAWN HAYES \\ Submitted to the Office of Graduate Studies of \\ Texas A\&M University \\ in partial fulfillment of the requirements for the degree of \\ MASTER OF SCIENCE
}

August 2009

Major Subject: Animal Science 


\title{
EFFECT OF TRACE MINERAL SUPPLEMENTATION ON GASTRIC ULCERS IN EXERCISING YEARLING HORSES
}

\author{
A Thesis
}

by

\section{ALEXA DAWN HAYES}

\author{
Submitted to the Office of Graduate Studies of \\ Texas A\&M University \\ in partial fulfillment of the requirements for the degree of \\ MASTER OF SCIENCE
}

\begin{abstract}
Approved by:
Chair of Committee, Dennis H. Sigler

Committee Members, Noah D. Cohen

Clay A. Cavinder

Head of Department, Gary Acuff
\end{abstract}

August 2009

Major Subject: Animal Science 


\begin{abstract}
Effect of Trace Mineral Supplementation on Gastric Ulcers in Exercising Yearling Horses.
\end{abstract}

(August 2009)

\author{
Alexa Dawn Hayes, B.S., Kansas State University \\ Chair of Advisory Committee: Dr. Dennis Sigler
}

Equine gastric ulcer syndrome (EGUS) has been reported to occur in $40 \%$ to over $90 \%$ of horses across multiple equestrian disciplines. The objective of this study was to evaluate the effect of trace mineral supplementation on gastric ulcers in exercising yearling horses. Twenty-one Quarter Horse yearlings, 15 to 18 mo of age, were randomly assigned to 1 of 3 treatment groups. The control group received no supplemental trace minerals, the inorganic group received supplemental sulfated trace minerals, and the organic treatment received supplemental amino acid complexed trace minerals. The trial consisted of 3 consecutive 28 - $d$ periods, separated by $5 \mathrm{~d}$ of diet acclimation. The basal ration included a $14 \% \mathrm{CP}$ textured concentrate, with coastal Bermudagrass hay fed in Periods 1 and 3 and alfalfa consumed in Period 2. In Periods 1 and 2, horses were exercised on a mechanical horse-exerciser, but were lunged or underwent training in an undergraduate course in Period 3. At the end of each period, horses were transported for $6 \mathrm{~h}, 5 \mathrm{~d}$ before being endoscopically examined to assign ulcer scores. Data were analyzed as repeated measures using the mixed procedure of 
SAS, with the model including fixed effects of treatment, period, and their interaction (SAS 9.2). All $P$-values $<0.05$ were considered significantly different.

Baseline EGUS scores were not different among treatment groups, with a mean of 2.1. There was no effect of treatment in any period, or a period by treatment interaction. There was a significant period effect $(P<0.01)$. Mean ulcer scores in Periods 1, 2, and 3 were significantly lower than baseline, with mean scores of 1.5, 1.0, and 1.5, respectively. There was a tendency $(P=0.06)$ for mean ulcer scores to be lower in Period 2 than in Periods 1 and 3, which were not different. Average daily intakes of $\mathrm{Zn}, \mathrm{Mn}, \mathrm{Cu}$, and $\mathrm{Co}$ were significantly higher in the organic and inorganic than control horses $(P<0.0001)$.

Under the conditions of this study, trace mineral supplementation did not affect gastric ulcer appearance and severity. However, it is possible that dietary and management alternatives, such as hay and concentrate types, could be anti-ulcerogenic. 


\section{DEDICATION}

To Cindy and Larry; I am blessed to call you my parents. You encourage me to reach for the stars and support me in every endeavor, even when it means being miles apart. Through leading by example, you instilled in me the importance of working hard and refusing to succumb to any of life's challenges. Above all, you've always provided a nourishing environment, equipping me with everything I needed: a listening ear, endless advice, and a door that will forever be open to the place we call home.

Brett, Kevin, and Logan, although there was never a shortage of fighting, arguing, or practical joking, you always challenge me to stand up for myself, my ideas, and my beliefs, while keeping me humble. I also appreciate that you all can give me a good laugh when I need it and even though we are each very different, we love each other and stand up for one another, no matter what.

Last but definitely not least, to my grandpa, Hurley, whose knowledge and experience surpass that of any textbook or class. Your humbleness astounds me and your passion for the agriculture industry has always been contagious. Horses and cattle bring out an excitement in you that is difficult to resist. Your calm, quiet, and softspoken nature is always reassuring. Finally, your loving and selfless demeanor is inspiring to us all. 


\section{ACKNOWLEDGEMENTS}

First and foremost, I would like to thank Dr. Dennis Sigler, my committee chair, for taking me on as a graduate student and giving me this opportunity. Additionally, I would like to thank my other committee members, Dr. Noah Cohen and Dr. Clay Cavinder for their assistance during my graduate career. I would especially like to thank Dr. Cohen for performing the endoscopic examinations and for his contributions to data collection. I would also like to thank Dr. Jason Sawyer for his assistance in data analysis, wisdom, genuine guidance, and patience. My sincere gratitude goes out to $\mathrm{Mr}$. Dave Golden and Krissy Johnson-Schroeder for their advice, encouragement, laughs, and willingness to assist with any obstacle or situation.

Next I would like to thank my fellow graduate students and colleagues for their friendships, conversations, and open arms as you welcomed me into the department. In particular, I would like to thank Kara Matheney, Cassidy Kurtz, and Jennifer Seale, as you all were there every step of the way, supporting and encouraging me, as well as putting a smile on my face when I needed it the most. You all were vital to my survival of this endeavor, and I am grateful I had you to share this experience with. I also sincerely appreciate the time and effort of Shannon Garey, Laura Caldwell, Bryan Agado, Pam Floyd, the 485s, undergraduate students, and horse center workers that assisted with this project.

Finally, my thanks go out to Zinpro for their generosity in supplying the funds to make this project possible. 


\section{NOMENCLATURE}

$\begin{array}{ll}\text { EGUS } & \text { Equine Gastric Ulcer Syndrome } \\ \text { CON } & \text { Control treatment group } \\ \text { INO } & \text { Inorganic treatment group } \\ \text { ORG } & \text { Organic treatment group } \\ \text { CB } & \text { Coastal Bermudagrass hay } \\ \text { ALF } & \text { Alfalfa }\end{array}$




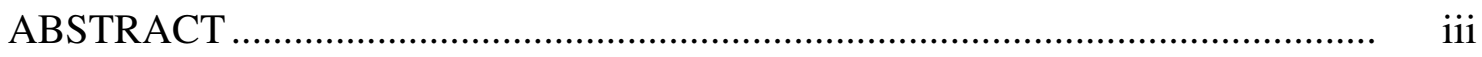

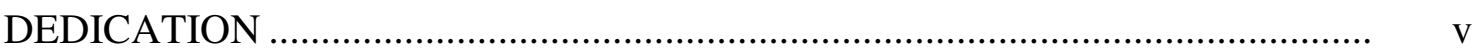

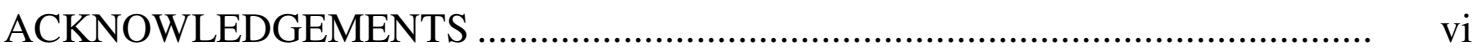

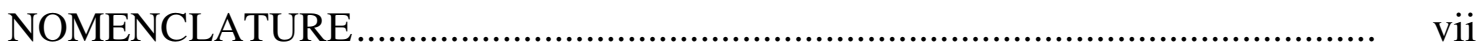

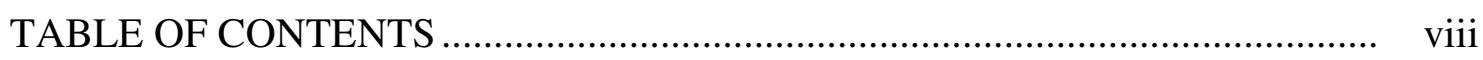

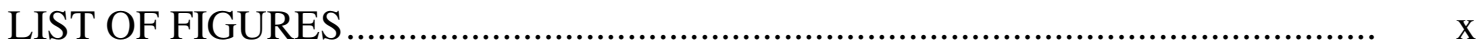

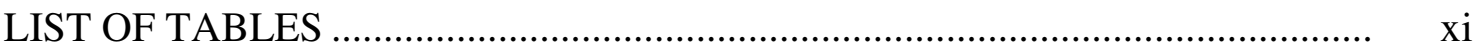

\section{CHAPTER}

I INTRODUCTION: THE IMPORTANCE OF RESEARCH................ 1

II LITERATURE REVIEW ...........................................................

Anatomy and Physiology ……………......................................... 3

Prevalence and Clinical Importance................................................. 7

Ulcer Diagnosis, Scoring, and Evaluation ....................................... 8

Risk Factors .......................................................................... 11

Current Treatment ..................................................................... 19

Trace Minerals........................................................................ 22

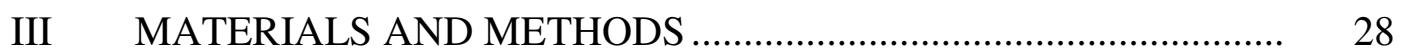

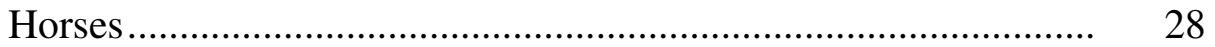

Experimental and Treatment Design ............................................ 28

Diet ............................................................................ 29

Endoscopic Examination.............................................................. 32

Housing ……....................................................................... 35

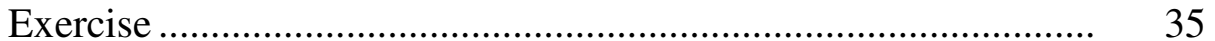

Transportation ..................................................................... 37

Statistical Analysis ................................................................... 37 
CHAPTER Page

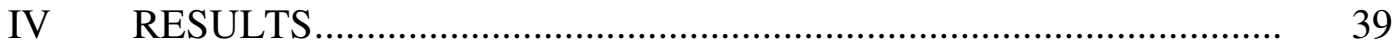

Ulcer Score ........................................................................ 39

Grain, Hay, and Supplement Intake.......................................... 44

Trace Mineral Intake.............................................................. 47

Growth Parameters ................................................................. 54

V DISCUSSION ............................................................... 57

Ulcer Score ......................................................................... 57

Grain, Hay, and Supplement Intake ......................................... 64

Trace Mineral Intake ....................................................... 65

Growth Parameters ........................................................... 67

VI SUMMARY AND CONCLUSIONS........................................... 71

LITERATURE CITED ....................................................................... 74

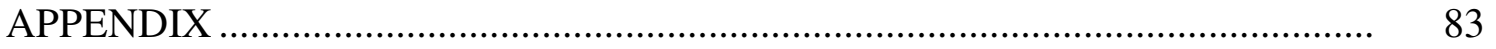

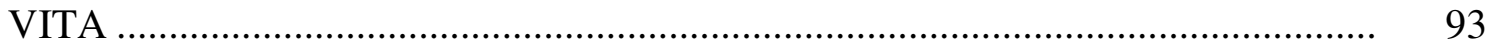




\section{LIST OF FIGURES}

Page

Figure 1 Percentage of yearling horses with ulcers or without ulcers in each period.

Figure 2 Mean EGUS scores of yearling horses in consuming no trace mineral (Control), inorganic trace mineral (Inorganic), or organic trace mineral (Organic) by period

Figure 3 Mean EGUS scores of yearling horses for period across all treatments consuming no, inorganic, or organic trace mineral .........

Figure 4 Change in ulcer score values between periods for yearling horses consuming no trace mineral (Control), inorganic trace mineral (Inorganic), or organic trace mineral (Organic) in each period ........

Figure 5 Mean body weights by day for yearling horses consuming no trace mineral (Control), inorganic trace mineral (Inorganic), or organic trace mineral (Organic) 


\section{LIST OF TABLES}

Page

Table 1 Analysis of feed sources used in diet formulation (100\% DM basis) 31

Table 2 Modified EGUC scoring system used to evaluate gastric ulcers in yearling horses.

Table 3 Number of horses assigned to each score in modified EGUC scoring system across all treatments for each period

Table 4 Ulcer scores of yearling horses fed no additional trace mineral $(\mathrm{CON})$, inorganic trace mineral (INO), or organic trace mineral (ORG)

Table 5 Change in ulcer scores in yearling horses being fed no trace mineral supplement $(\mathrm{CON})$, inorganic trace mineral (INO), or organic trace mineral (ORG).

Table 6 Mean intake of grain, hay, and supplement for all periods in yearling horses consuming no trace minerals $(\mathrm{CON})$, inorganic trace minerals (INO), or organic trace minerals.

Table 7 Period 1 mean daily nutrient intake from hay and grain in yearling horses consuming no $(\mathrm{CON})$, inorganic (INO), or organic (ORG) trace minerals (100\% DM basis)

Table 8 Period 2 mean daily nutrient intake from hay and grain in yearling horses consuming no $(\mathrm{CON})$, inorganic (INO), or organic (ORG) trace minerals (100\% DM basis)

Table 9 Period 3 mean daily nutrient intake from hay and grain in yearling horses consuming no $(\mathrm{CON})$, inorganic (INO), or organic (ORG) trace minerals (100\% DM basis)

Table 10 Average daily intake of zinc, manganese, copper, and cobalt from . grain fed to yearling horses supplemented with no trace minerals (CON), inorganic trace minerals (INO), or organic trace minerals (ORG) (mg/hd/d) 
Table 11 Average daily intake of zinc, manganese, copper, and cobalt by period in yearlings consuming different types of hay and being supplemented with no trace minerals $(\mathrm{CON})$, inorganic trace minerals (INO), or organic trace minerals (ORG) $(\mathrm{mg} / \mathrm{hd} / \mathrm{d})$

Table 12 Average daily intake of zinc, manganese, copper, and cobalt from trace mineral supplements in yearlings receiving no supplementation (CON), inorganic trace minerals (INO), and organic trace minerals $(\mathrm{ORG})(\mathrm{mg} / \mathrm{hd} / \mathrm{d})$

Table 13 Average total daily intake of the trace minerals zinc, manganese, copper, and cobalt in yearling horses supplemented with no trace minerals $(\mathrm{CON})$, inorganic trace minerals (INO), or organic trace minerals (ORG) by period (mg/hd/d) (100\% DM basis)

Table 14 Average daily intake of zinc, manganese, copper, and cobalt in yearlings supplemented with no trace mineral $(\mathrm{CON})$, inorganic trace mineral (INO), or organic trace mineral (ORG) across all periods (100\% DM basis).

Table 15 Average daily intake of zinc, manganese, copper, and cobalt across all treatments by period (100\% DM basis)

Table 16 Growth parameters, including body condition score (BCS), body body weight (BW), total gain, and average daily gain (ADG) of yearling horses supplemented with no trace minerals $(\mathrm{CON})$, inorganic trace minerals (INO), or organic trace minerals (ORG)....

Table 17 Mean daily nutrient intake of yearling horses by period across all treatment groups in reference to the NRC (2007)

Table 18 Average daily intake of trace minerals across all 3 periods by treatment group in reference to the NRC (2007). 


\section{CHAPTER I}

\section{INTRODUCTION: THE IMPORTANCE \\ OF RESEARCH}

Equine gastric ulcer syndrome (EGUS) is a health condition that affects horses at various stages of life, from foals a few days of age to mature horses (Buchanan and Andrews, 2003). This condition is a dynamic ailment that has recently become a focus of research. Due to its multifaceted and complex nature, the specific pathogenesis of gastric ulcer formation in the equine remains unclear (Bell et al., 2007a). It has been reported that EGUS is a prevalent condition across multiple equestrian disciplines, from racehorses to recreational show horses (Murray et al., 1996; McClure et al., 2005a). It is estimated that EGUS occurs in $40 \%$ to over $90 \%$ of horses, with various factors implicated as contributing to ulcer development including stress, feed deprivation, intensive training, stall confinement, diet, and transportation (Furr et al., 1992; Murray and Eichorn, 1996; Vatistas et al., 1999a; Nadeau et al., 2000; Lorenzo-Figueras and Merritt, 2002; McClure et al., 2005b; Bell et al., 2007a; White et al., 2007). Given that EGUS could be detrimental to health and athletic performance, pharmaceuticals have been employed for the treatment and prevention of ulcers. These products can be expensive. Consequently, investigations have been conducted to identify more economical alternatives for managing horses to reduce the incidence of EGUS.

This thesis follows the style of Journal of Animal Science. 
Preliminary research has indicated a reduction in intestinal lesions in broilers fed Zn amino acid complexes, attributed to the role $\mathrm{Zn}$ plays in epithelial tissue integrity and cellular repair (Zinpro, 2004). Studies have also found reduced ulcer scores and higher stomach pH with alfalfa-grain diets (Nadeau et al., 2000), along with a reduction in ulceration while feeding alfalfa hay as opposed to grass hay in yearling horses (Lybbert, 2007). Therefore, this study was designed to further investigate possible dietary alternatives that could be anti-ulcerogenic. The specific objectives of this study were to:

1. evaluate the effect of trace mineral supplementation on gastric ulcers in exercising yearling horses; and,

2. determine the influence of hay type on gastric ulcer appearance and severity. 


\section{CHAPTER II}

\section{LITERATURE REVIEW}

\section{Anatomy and Physiology}

The anatomy of the equine stomach predisposes horses to the development of gastric ulcers. The equine stomach is composed of 2 primary regions, the non-glandular and glandular regions. The non-glandular portion is the proximal one-third of the stomach, is covered by stratified squamous epithelium, and contains few secretory glands (Andrews and Nadeau, 1999). The stratified squamous mucosa that covers the non-glandular region is comprised of 4 layers. The stratum corneum (SC), stratum transitionale (ST), stratum spinosum (SS), and stratum basale (SB) are arranged from the lumen of the stomach (SC) to the deepest tissue layer where cell germination occurs (SB) (Argenzio, 1999). The glandular region makes up the remaining ventral two-thirds of the stomach and contains glands that secrete hydrochloric acid $(\mathrm{HCl})$, pepsinogen, bicarbonate, and mucus (Andrews and Nadeau, 1999). The non-glandular and glandular regions are separated by the margo plicatus, which is where the thickest epithelium can be found (Murray et al., 2001a). This also is the most common site of gastric ulceration (Murray et al., 1989; Murray, 1992; Murray, 1999; Vatistas et al., 1999b; Begg and O’Sullivan, 2003).

In light of the equine stomach anatomy, regional functionality may play a role in ulcer formation. Non-glandular ulcers represent about $80 \%$ of all ulcers, with glandular ulcers being rare (Buchanan and Andrews, 2003). The development of EGUS is most 
likely a result of an imbalance between acidic secretions and protective mechanisms. Acid exposure probably leads to ulceration in the non-glandular region with a defect in mucosal secretions of mucus and bicarbonate, or inhibition of mucosal blood flow contributing to glandular ulcers by impairing protective mechanisms, which could lead to acidic damage (Murray, 1999). The acidity of the equine stomach increases from the esophageal region to the pylorus, with $\mathrm{pH}$ being close to neutral and as low as 1.5 , respectively (Andrews and Nadeau, 1999). Since the non-glandular epithelium lacks protective barriers, contact with acidic fluid or low gastric $\mathrm{pH}$ can cause cellular damage eventually leading to necrosis of tissue and appearance of ulcers. The high ulceration rate of the margo plicatus is probably due to the level of acid exposure at this location (Murray, 1999; Begg and O’Sullivan, 2003; Dionne et al., 2003; Hewetson et al., 2006). Although there is documentation that the greater and lesser curvatures are comparably affected, the lesser curvature is considered a dynamic region of the stomach and encounters the highest amount of gastric acid. Thus, it also is a common site for ulcer formation (Begg and O’Sullivan, 2003; Dionne et al., 2003). Exposure of squamous epithelial for more than 4 hours to low $\mathrm{pH}$ (i.e. $\mathrm{pH} \leq 4.0$ ) can lead to ulceration (Andrews et al., 2006a). Additionally, alteration in squamous mucosal bioelectric properties, which leads to mucosal damage, can occur within 30 minutes of introducing acid (Widenhouse et al., 2002). Given the glandular region of the stomach has more extensive protective mechanisms than the non-glandular squamous mucosa, difference in tissue type could explain the reduced appearance and severity of glandular ulcers (Begg and O'Sullivan, 2003). Mucus and bicarbonate create a protective barrier between the 
glandular mucosa cells and the lumen of the stomach. Acidic molecules are allowed to readily diffuse from the mucosa cells through this barrier to the lumen of the stomach. However, this transport is only 1-way, with the reverse movement of molecules being prohibited. Thus, the glandular cells are protected by the bicarbonate-rich mucus layer from invasion by backflow of ions and the acidic environment of the glandular region (Andrews and Nadeau, 1999; Merritt, 2003). Although not as extensively discussed as mucous and bicarbonate production, glandular blood supply plays a vital role in mucosa health. Adequate blood flow provides nutrients necessary for bicarbonate and mucus production, as well as the means to repair damaged cells (Murray, 1999; Wallace, 2001). Recent documents have also suggested the importance of epidermal growth factor (EGF) in healing gastric ulcers. This growth factor can be found in the saliva and promotes cell proliferation and DNA synthesis of epithelial cells, which could expedite mucosal repair. Receptors of EGF are also up-regulated in areas of high cellular turnover and ulcerated regions, including feed deprivation induced ulcers in horses. Therefore, EGF could play a vital role in stomach tissue restoration (Jeffrey et al., 2001; Buchanan and Andrews, 2003; Bell et al., 2007a).

Even though exact mechanisms have not been determined, several mechanisms within the stomach are thought to contribute to mucosa damage, such as hydrochloric acid ( $\mathrm{HCl}$ ), volatile fatty acids (VFAs), bile acids, and pepsin, with $\mathrm{HCl}$ being the most accepted culprit (Berschneider et al., 1999; Argenzio, 1999; Nadeau et al., 2003). Since epithelial function and tissue health are measured by sodium ion transport, histological slides of cellular swelling and damage are attributed to a decrease in sodium transport 
and an increase in cell permeability. According to Andrews et al. (2006a), the fact that cell permeability is altered prior to a reduction in sodium ion transport suggests that an increase in hydrogen ions acidifies cells in multiple layers, decreases sodium transport, and induces cellular swelling. When fluid intracellular volume exceeds the cellular capacity, apoptosis occurs. Eventually, this leads to ulcerated regions (Argenzio and Eisemann, 1996). Sodium transport decreased and barrier permeability increased rapidly after $\mathrm{HCl}$ exposure at a $\mathrm{pH}$ of 1.5 , but increased to levels comparable to control samples when calcium carbonate was added. Therefore, calcium carbonate was capable of reversing acid-induced cellular damage (Andrews et al., 2006a).

Volatile fatty acids also have been proposed to contribute to ulcer formation. In pigs, it has been shown that VFAs can damage squamous epithelium in an acidic environment. Because many performance horses are fed a high concentrate diet, like pigs, it is possible that this same mechanism occurs in horses (Andrews and Nadeau, 1999). In a study considering the impact of VFAs on cellular health, each VFA had a concentration-dependent response that varied relative to $\mathrm{pH}$, with acetic acid being the most damaging at a $\mathrm{pH}<4.0$ and valeric acid effecting tissue at a $\mathrm{pH} \leq 7.0$. When the $\mathrm{pH}$ is $<1.5$, acetic acid causes a reduction in sodium transport and increases cell permeability, leading to the observation of a histological change. However, both sodium transport and cell permeability return to control levels with calcium carbonate treatment. Sodium transport and barrier permeability are compromised in a concentration dependent manner for propionic, butyric, and valeric acid (Andrews et al., 2006a). These effects were reversed for propionate and butyrate by adding calcium carbonate, 
but not for valeric acid. It has been suggested that VFA chain length also is associated with barrier function, as longer chain VFAs could be more damaging to epithelial cells (Nadeau et al., 2003; Andrews et al., 2006a). Acetic acid concentration accounted for 91.6\% of all VFAs in tissue. Although exposing tissue to butyric acid, propionic acid, and valeric acid increased the concentrations of these VFAs, their levels continued to be minimal relative to acetic acid. This led the authors to speculate that acetic acid may permeate non-glandular epithelial more readily than the other VFAs measured, therefore being more damaging to gastric cells (Andrews et al., 2006a).

When combined with an acidic environment, bile salts and pepsinogen can increase hydrogen ion permeability in the non-glandular portion of the stomach and potentially cause damage. It has been suggested that a reflux of bile acids into the stomach from the duodenum is a cause of ulcers in the pylorus. However, this would expose the pylorus to a high concentration of bile acids, theoretically causing severe glandular ulcers. Since this is not the case and pyloric ulcers are milder in nature than those in the non-glandular region, it is possible that bile acids do not play a significant role in ulcer formation (Begg and O'Sullivan, 2003). Pepsinogen is activated by $\mathrm{HCl}$, so a $\mathrm{pH}<4$ is required for cellular damage. Therefore, both of these components must act

synergistically with $\mathrm{HCl}$ in order to be ulcerogenic (Berschneider et al., 1999).

\section{Prevalence and Clinical Importance}

Equine gastric ulcer syndrome occurs in $40 \%$ to $>90 \%$ of mature horses and $25 \%$ to $50 \%$ of foals (Andrews et al., 1999; Bertone, 2000; Murray et al., 1996). 
Glandular ulcers are typically found in foals, with non-glandular lesions being the primary diagnosis in yearlings and mature horses (Bell et al., 2007a; Bezdekova et al., 2007). Gastric ulceration in foals can result in abdominal pain and gastric or duodenal perforation (Furr et al., 1992). Depending on discipline and management, EGUS occurs in $58 \%$ to $100 \%$ of horses in training (Bell et al., 2007a). Gastric ulcers also were discovered in half of horses euthanized for various medical reasons, with unknown medical histories (Andrews et al., 2006a). In addition to being a health concern, EGUS also could inhibit performance of the equine athlete. In a report of risk factors for gastric ulcers in Swedish Standardbreds, there was a weak association between the difference in actual and expected performance by the trainer and gastric ulcer score (Jonsson and Egenvall, 2006). Mitchell (2001) also concluded that EGUS was a cause of poor performance in hunter/jumpers and dressage horses. Additionally, poor performance was associated with ulceration in Thoroughbred race horses (Vatistas et al., 1999b).

\section{Ulcer Diagnosis, Scoring, and Evaluation}

Diagnosis of EGUS relies on endoscopic examination because clinical signs are vague and not entirely specific to gastric ulcers (Bell et al., 2007c). Also, there are no reliable, consistent biochemical markers that can diagnose the presence and severity of gastric ulcers (Murray et al., 1996; EGUC, 1999; Vatistas et al., 1999a). However, there are some general characteristics associated with horses having gastric ulcers. Horses with a history of colic, poor hair coat, and those that were considered selective eaters were more likely to have gastric ulceration (Vatistas et al., 1999a). Additionally, a poor 
appetite, low body condition score, and change in attitude have been suggested (EGUC, 1999). When compared with horses showing no signs, horses expressing clinical signs of ulceration had more severe gastric ulcers (Murray et al., 1989). Of horses evaluated for abdominal pain, $49 \%$ had gastric ulceration. The severity of the ulcers in these horses was high, with half assigned the highest score possible on that particular scoring system (Dukti et al., 2006). On the other hand, in a study of 23 mixed-breed yearlings who never exhibited clinical signs of gastric ulceration, all had non-glandular ulcers at endoscopy and necropsy (Andrews et al., 2002). Moreover, there is no association between appearance of ulcers in the glandular and non-glandular portions of the stomach. Therefore, it is necessary to evaluate the pylorus in addition to the body of the stomach during endoscopic examination, regardless of whether or not ulcers are detected (Begg and O’Sullivan, 2003).

If applicable, a blood test or accurate biochemical marker could provide a practical, non-invasive screening method for ulcers in horses. Sucrose permeability tests have been used to access gastrointestinal integrity and functionality. After oral administration of sucrose, there was a significant increase in serum sucrose concentrations in horses with moderate to severe gastric ulcers (Hewetson et al., 2006). Inducing gastric ulcers in horses also resulted in an increase in urine sucrose concentrations (O’Connor et al., 2004). However, specificity of the test would require a strong correlation between sucrose concentration and ulcer severity, so further research is warranted. Although sucrose permeability has shown some promise as a non-invasive screening test for gastric ulcers, endoscopic examination continues to be the accepted 
method for detection and diagnosis of gastric ulcer appearance and severity (Reese and Andrews, 2009).

Numerous scoring systems for assessing the appearance and severity of ulcers, as well as evaluating possible causes and treatment options, have been reported. Most investigators or research groups have developed their own scoring system, usually tailored to meet the needs of their specific EGUS research and clinical interests (Furr and Murray 1989; Murray et al., 1989; MacAllister et al., 1997; Andrews et al., 1999; Vatistas et al., 1999a,b; Merritt, 2003; Orsini et al., 2003; Nieto et al., 2004). Without a standard scoring system, evaluation of gastric ulcers both in research and clinical settings is limited. It also inhibits investigators from comparing results among studies (Bell et al., 2007c). Inferences from previous research conducted and possible relationships among investigations must also be considered carefully because of the variability in scoring systems used to evaluate EGUS.

Establishing a valid ulcer scoring system would allow more accurate assessment of ulcer number and severity, as well as strengthening the ability of researchers to evaluate gastric ulceration and compare treatment options. When comparing ulcer scores assigned at endoscopy, necropsy, and histology, the endoscopist underestimated the severity of ulcers $57 \%$ of the time (Andrews et al., 2002). When score was based on the number of gastric lesions, there was a difference between scores assigned by the endoscopist and those determined at necropsy. However, there was not a difference between endoscopy and necropsy score when ulcers were classified by size (Andrews et al., 2002). In another study, endoscopists were asked to grade the same set of stomachs 
using both the Equine Gastric Ulcer Council's (EGUC) suggested grading system and a number/severity scoring system proposed by MacAllister et al. (1997). There was no significant difference between scores when both examiners used the EGUC scoring system. However, there was a difference between scores when endoscopists used the number/severity system. Additionally, examiners commented on the ease of use of the EGUC system compared to the number/severity approach (Bell et al, 2007c).

Moreover, use of a 4-point scoring system, based on ulcer size and number, had $72 \%$ agreement between 5 independent, experienced endoscopists (Hewetson et al., 2006).

\section{Risk Factors}

Although ulcers are typically attributed to physiologic stress, it is quite possibly specific stressors and not stress in general that lead to gastric ulcer formation. For example, foals experiencing the physiological stress of disease have a greater prevalence of ulceration than do their healthy counterparts. Disease also influenced the location of ulceration with diseased foals displaying significantly more glandular ulcers than normal foals. However, the occurrence of squamous ulceration adjacent to the margo plicatus does not appear to be influenced by disease (Furr et al., 1992). The association of disease with gastric ulceration may not be related to stress per se. Cortisol has been well documented as a hormonal indicator of stress across multiple species, indluding horses (Alexander and Irvine, 1998). Cortisol concentrations did not differ between normal foals and those stressed by disease (Furr et al., 1992). Moreover, recent studies in mature horses have reported that there is no association between cortisol concentration 
and gastric ulcer formation (Vatistas et al., 1999a,b). Therefore, risk factors for EGUS other than stress have been investigated.

Exercise is one of the primary risk factors for EGUS across various equine disciplines, including race horses, western performance, endurance, recreational show horses, and riding lesson horses. It has been well documented that gastric ulcer incidence increases with exercise intensity and training (Murray et al., 1989; Murray et al., 1996; Vatistas et al., 1999b; McClure et al., 1999; Bertone, 2000; Lorenzo-Figueras and Merritt, 2002; Rabuffo et al., 2002; Nieto et al., 2004; Bell et al., 2007c; White et al., 2007). For example, Thoroughbreds in race training had higher incidence of ulceration than those not in training, and actively racing Standardbreds were more likely to have ulcers than inactive horses (Murray et al., 1989; Dionne et al., 2003). Moreover, in a study of risk factors associated with Swedish Standardbred racehorses, status of training was the only factor to have a significant association with ulceration. Horses that had raced at least once in the previous month, or were in race preparatory training had a higher risk to develop ulcers than those that had completed their training, but had not been raced in a month; $70 \%$ of those horses in various stages of training had at least 1 non-glandular ulcer (Jonsson and Egenvall, 2006). Vatistas et al. (1999b) evaluated the effect of race training on inducing gastric ulcers in Thoroughbred race horses. The study included both horses previously conditioned to race training and those turned out to pasture. Baseline endoscopies revealed that all horses actively training had ulcers, while those maintained in pasture had a low incidence of ulceration. However, all horses developed ulcers within 14 days of initiating simulated race training (Vatistas et al., 
1999b). In ulcer-free horses, 8 days of discipline-specific training caused ulceration in $73 \%$ of untreated horses and $12 \%$ of omeprazole treated horses (White et al., 2007). Therefore, horses involved in intense training regimens and competition are at increased risk for developing ulcers than those that are not.

Because the training process, especially for race horses, involves several of the risk factors for gastric ulcers, it is highly likely that untreated horses in training will have recurrence or progression of ulcer severity (Doucet et al., 2003); spontaneous healing is rare in horses in training. In fact, ulceration worsened in horses that continued to train without treatment (Murray et al., 1996; Andrews et al., 1999). Thoroughbred race horses who displayed ulceration continued to increase in ulcer score as training continued without treatment (Murray et al., 1997; Lester et al., 2005). In a study investigating the effects of short-term omeprazole treatment on Quarter Horses in race training, Quarter Horses in western performance training, and Thoroughbreds exercising to fatigue on a mechanical exerciser, $88 \%$ of treated horses were ulcer-free in 8 days, while only $27 \%$ of untreated horses were ulcer-free (White et al., 2007).

Exercise could contribute to ulceration via several avenues. First, the mechanics of an exercising horse, in particular intra-abdominal pressure, increases the time portions of the squamous epithelial cells are exposed to an acidic environment. It has been documented that, as horses exercise, the volume of the stomach decreases concomitant with an increase in intra-abdominal pressure (Lorenzo-Figueras and Merritt, 2002). Physiologically, this could force contents from the ventral portion of the stomach forward. The $\mathrm{pH}$ of the proximal stomach also declines, which could lead to gastric 
ulcer formation. It also was reported that all horses subjected to a treadmill exercise regimen developed ulcers (Lorenzo-Figueras and Merritt, 2002). Delayed gastric emptying could increase the exposure of epithelial to acidic contents, so the decrease in gastric emptying rate during exercise might lead to ulceration as well (Andrews and Nadeau, 1999). Additionally, gastrin stimulates acid production in the equine stomach. Exercising horses have an increase in gastrin concentration, which could contribute to a decrease in stomach pH (Furr et al., 1994). Finally, a rigorous training program could divert blood flow to muscle, which reduces blood flow available for mucosal maintenance and repair (Collier, 1999).

Intermittent feed deprivation and/or alteration in eating behavior has also been reported as a risk factor for EGUS. Alternating 24 hours of fasting with 24 hours of $a d$ libitum forage consumption induced ulcer formation within 84 hours (Murray, 1994). This protocol of ulcer induction has been widely successful in research investigations (Murray and Eichorn, 1996; Jeffrey et al., 2001; O’Connor et al., 2004). Horses continuously secrete $\mathrm{HCl}$, so undergoing long periods of time with an empty stomach could lead to mucosal damage, as feed contents are not present to buffer the acidic environment (Campbell-Thompson and Merritt, 1987). Additionally, forage consumption stimulates saliva production, which plays an imperative role in neutralizing the acidity of the stomach. Therefore, low forage diets could make horses more susceptible to ulceration by reducing saliva production, which could lead to a lower stomach pH (Bell et al., 2007a). Furthermore, any situation that deprives a horse from feed or decreases dry matter intake could predispose them to EGUS. 
The effects of stall confinement on ulcer formation could be associated with feeding behavior and the intermittent feed deprivation discussed above. Horses at pasture have been reported to have lower incidence of gastric ulcers, possibly due to continuous grazing, which produces saliva and allows the combination of saliva and feedstuffs to buffer the acidic environment of the stomach (Buchanan and Andrews, 2003). Additionally, stalled horses could undergo periods of feed deprivation in the middle of the day, since most stalled horses receive 2 meals daily. It is also possible that isolating horses or removing herd mates causes social distress, which leads to a decrease in dry matter intake, and can contribute to ulcer formation (McClure et al., 2005a). It has been reported that stalled horses who have ulcers improve within 7 to 9 days at pasture (Murray and Eichorn, 1996). Conversely, more recent studies show that horses turned out to pasture have a high incidence of gastric ulcers (Holbrook et al., 2005; le Jeune et al., 2008). Furthermore, horses in New Zealand are commonly turned out to pasture while in race training, which is different than race horse housing in the United States. This observation, coupled with the notion that allowing horses with ulcers access to pasture might alleviate their condition, led authors to conduct a field study involving race horses in training. There was no difference in ulcer scores of horses turned out to pasture full time, those turned out for at least 4 hours per day, or individuals housed in stalls (Bell et al., 2007b). It recently has been reported that the $\mathrm{pH}$ of the proximal stomach has a circadian pattern, being lower in the morning than evening, even in horses turned out in paddocks with ad libitum hay (Husted et al., 2008). This could explain the higher than expected incidence of ulcers in pasture horses. Lester et al. (2005) also 
reported a high variability in ulcer scores across 8 race horse stables, which partially was attributed to the drastic differences in housing and management observed by investigators. Therefore, the effect of housing type continues to be the subject of speculation and investigation and remains unclear.

Recently, diet has been given increased attention in EGUS research both as a risk factor and as a possible non-pharmacological treatment option. The high carbohydrate diet of performance horses can lead to ulceration as these concentrates consist of rapidly fermented carbohydrates, which can decrease $\mathrm{pH}$. Horses on these rations also have high serum gastrin levels (Andrews et al., 2005). It also is proposed that horses being fed greater than $0.5 \mathrm{~kg} / 100 \mathrm{~kg}$ bodyweight in grain every 6 to 8 hours are at an increased risk for non-glandular gastric ulcers, as concentrate feeds are high in acetic acid. This could cause epithelial damage, especially at a low pH (Andrews et al., 2006a). Additionally, meal size and composition might play a role in ulcer formation through gastric emptying rate. Meals that are larger and have higher starch content also have a slower gastric emptying rate, which could result in epithelial cells being exposed to acidic digesta for an extended period of time (Metayer et al., 2004).

Dietary oil supplementation has resulted in mixed results. In 1 study, feeding dietary oils did not reduce the number or severity of non-glandular gastric ulcers in mares (Frank et al., 2005). However, another investigation suggests corn oil supplementation enhances gastric juice $\mathrm{PGE}_{2}$ concentration and reduces acid secretion in pony foals. Corn oil also stimulated sodium release, which could lead to an increased concentration of sodium bicarbonate to buffer stomach $\mathrm{pH}$. Corn oil could be beneficial 
in cases of deficiencies of mucosal defences, such as glandular ulcers or those induced by non-steroidal anti-inflammatory drugs (NSAIDs) (Cargile et al., 2004).

Hay type also has been an area of recent investigation. Horses on an alfalfa-grain diet had higher stomach pHs and lower appearance and severity of gastric ulcers than horses consuming only grass hay (Nadeau et al., 2000). Furthermore, yearling horses fed alfalfa hay had significantly lower ulcer scores than those fed grass hay (Lybbert, 2007). It is possible that the high calcium and high protein nature of alfalfa have a protective effect for the squamous mucosa (Nadeau et al., 2000). Without regard to hay type, forage consumption in general stimulates saliva production, which plays an imperative role in neutralizing the acidic environment in the stomach. Therefore, low forage diets could make horses susceptible to ulceration by reducing saliva production, which could lead to a lower stomach pH (Bell et al., 2007a). The variability in both the dietary components investigated and results reported support further research into the effects of diet on ulcerogenesis and as a method of prevention or treatment.

Although transportation has not been directly studied as a contributor to gastric ulcers, it has been discussed in several articles (MacAllister and Sangiah, 1993; McClure et al., 1999; McClure et al., 2005a). It is possible that horses contract their abdominal muscles, as they do during exercise, which could increase the risk for developing ulcers (McClure et al., 2005a). It also is typical for horses to have reduced feed intake following transport which could increase acidity in the same fashion as feed deprivation (Buchanan and Andrews, 2003). 
Non-steroidal anti-inflammatory drugs were originally thought to be a primary cause of EGUS. Although early studies induced ulcers using a product of this type, more recent data provides evidence to the contrary. Ulcers have been induced without the use of these drugs and field reports have found no association between using NSAIDs and squamous gastric ulcers (Murray et al., 1989; Murray, 1992; MacAllister et al., 1992; Murray et al., 1996; Vatistas et al., 1999b; Andrews et al., 2005). These products are more strongly associated with glandular than non-glandular ulcers (Murray et al., 1996; Collier and Stoneham, 1997; Vatistas et al., 1999b; Monreal et al., 2004). Considering NSAIDS inhibit $\mathrm{PGE}_{2}$, the protective abilities of the glandular region are compromised through decreased bicarbonate production, increased gastric acid production, and decreased mucosal blood flow. Manipulating these functions could lead to glandular ulceration (Andrews and Nadeau, 1999; Buchanan and Andrews, 2003).

The prevalence of ulcers in Standardbreds is lower than in Thoroughbreds. It is possible that the calmer nature of the Standardbred breed contributes to this difference, with these horses rarely requiring sedation for endoscopy (Dionne et al., 2003). Only 2 of 20 Standardbreds evaluated required sedation during 1 of 4 endoscopies (Doucet et al., 2003). However, a study involving both Quarter Horses and Thoroughbreds receiving EGUS treatment or sham-dosing documented that in the sham-dosed horses more Thoroughbreds were ulcer-free than Quarter Horses (White et al., 2007). In consideration of demeanor in general, McClure et al (1999) reported horses deemed to have a nervous disposition were more likely to have ulcers. 
Given the numerous risk factors and projected causes of EGUS, any single factor or several working synergistically could contribute to ulcer development. Knowing the risk factors, along with their suspected causal mechanisms is advantageous when evaluating a horse suspected of EGUS to facilitate diagnosis and treatment.

\section{Current Treatment}

Because the equine gastric squamous mucosa is histologically more similar to the human esophageal mucosa than the human gastric mucosa, EGUS is thought to be similar to gastro-oesophageal reflux disease syndrome (GERDS) in humans (Andrews and Nadeau, 1999). The primary site of gastric ulceration in the horse, the margo plicatus, is anatomically analogous to the gastro-oesphageal junction in man (Collier, 1999); therefore, typical medicinal treatments of EGUS are based on human GERDS treatment, which heavily relies on maintaining gastric fluid at a $\mathrm{pH}>4.0$. This provides a more basic environment that is conducive to ulcer healing (Andrews et al., 2006b). It has been documented that increasing stomach $\mathrm{pH}$ above 4.0 can reverse acidic damage (Andrews et al., 2006a). Healing depends on ulcer severity, location, and stomach environmental conditions. It can begin within 24 hours of mucosal damage and be completed in as little as 7 days, or remain for 3 months or longer. Superficial ulcers, erosions, or those in the glandular region heal at a more rapid rate than deep, nonglandular ulcers (Murray et al., 1989; Murray et al., 2001b; Bell et al., 2007a). Gastric ulcers in humans are normally found in the antrum, which is just prior to the pylorus, and are normally caused by a Helicobacter pylori bacterial infection or NSAIDs (Collier, 
1999). Helicobacter pylori has not been associated specifically with gastric ulcers in horses (Bell et al., 2007a). So, treatment and prevention focuses on acid suppression via pharmaceuticals rather than antibiotic treatment, as in the case of human ulcers.

The only Food and Drug Administration (FDA)-approved product for the treatment and prevention of gastric ulcers in horses is the proton pump inhibitor omeprazole (Buchanan and Andrews, 2003). Omeprazole is a chemical in the substituted benzimidazole class of acid suppression products (McClure et al., 2005a). It inhibits acid secretion by irreversibly binding the enzyme $\mathrm{H}+\mathrm{K}+\mathrm{ATPase}$ (proton pump). This pump facilitates acid production in the last step of acid secretion in the gastric parietal cell by exchanging a potassium $(\mathrm{K}+)$ ion for a hydrogen $(\mathrm{H}+)$ ion. The hydrogen ion is released into the lumen of the stomach to combine with chloride to form hydrochloric acid (Fellenius et al., 1981). The irreversible binding of $\mathrm{H}+\mathrm{K}+\mathrm{ATPase}$ allows extended duration of acid secretion, which allows the feasibility of once daily dosing. Since omeprazole inhibits acid production at the proton pump, it suppresses acid secretion regardless of stimulant. Therefore, it has been proven to be an extremely effective pharmaceutical treatment for both ulcer healing and prevention (Murray et al., 1997; Andrews et al., 1999; Merritt et al., 2003; Orsini et al., 2003; McClure et al., 2005a,c; White et al., 2007).

The effective dose for both healing and ulcer prevention have been investigated. In horses, $4 \mathrm{mg} / \mathrm{kg} \mathrm{BW}$ of omeprazole is administered for 28 days to reduce acid secretion and treat ulcers. However, the common dosage of the same drug in humans is only $0.3 \mathrm{mg} / \mathrm{kg}$ BW (Andrews et al., 1999; Collier, 1999). Gastric ulcer score was 
reduced and stomach $\mathrm{pH}$ increased with a commercial paste omeprazole dose of $4 \mathrm{mg} / \mathrm{kg}$ BW administered every 24 hours in race horses in training. Although $2 \mathrm{mg} / \mathrm{kg} \mathrm{BW}$ has been documented as an adequate preventative dose, a $1 \mathrm{mg} / \mathrm{kg} \mathrm{BW}$ dose was reported to be effective against ulcer recurrence. However, the dosage of omeprazole may have to be higher in horses with an inherently lower gastric juice $\mathrm{pH}$ in order to successfully increase $\mathrm{pH}$ above 4.0. When treatment was discontinued, $90 \%$ of horses had recurrence of gastric ulcers within 28 days. Additionally, untreated horses who remained in training did not display spontaneous healing (Andrews et al., 1999; Doucet et al., 2003; White et al., 2007).

Ranitidine, cimetidine, and sucralfate are 3 additional gastric ulcer treatment products that have been investigated. Ranitidine and cimetidine are histamine-2 $\left(\mathrm{H}_{2}\right)$ receptor antagonists. They competitively inhibit histamine, which stimulates gastric acid secretion, from binding to $\mathrm{H}_{2}$ receptors on the parietal cell, thus suppressing acid section. However, the affects are limited, as inhibition is specific to histamine-stimulated acid secretion. Ranitidine is about 4 times as potent as cimetidine as an acid suppressant. Sucralfate forms a gel-like substance in the stomach and adheres to ulcerated regions. This prevents further acid damage and aids in ulcer healing. Although these treatment methods have shown some effectiveness, they have low bioavailability, require large doses, and must be administered several times a day (Murray and Eichorn, 1996). So, their overall effectiveness has been lower than omeprazole (Orsini et al., 2003; Lester et al., 2005). 
Products that suppress acid production provide a gastric environment conducive to ulcer healing, and typical clinical EGUS therapies are effective. However, they also are expensive, which limits their practicality. Additionally, it is possible that continuous use of acid-suppressants has health ramifications. The acidic nature of the stomach serves several beneficial biological functions, such as aiding in digestion and defending the body from pathogen invasion. Since protein digestion begins in the stomach, chronically increasing $\mathrm{pH}$ might decrease protein digestion. Also, a more neutral stomach could be more susceptible to infection. Human studies have reported that acidsuppressive therapy was associated with bacterial and viral infections (Laheij et al., 2003; Dial et al., 2005). Therefore, the necessity for alternative anti-ulcerogenic treatment options is critical beyond an economic standpoint.

\section{Trace Minerals}

Trace minerals are necessary in minute concentrations in the diet, but are necessary for proper growth and biological function. In yearling horses, trace minerals are vital for skeletal development and tissue maintenance. Traditionally, zinc, manganese, copper, and cobalt are the trace minerals collectively supplemented (Ott and Asquith, 1989,1995; Ott and Johnson, 2001; Wagner et al., 2005). Although these trace elements are generally associated with bone and cartilage health, it is possible that they have additional biological functions that could be useful in gastric ulcers.

Zinc is essential for proper growth and development of all animals and is required through all stages of life. It is found in every tissue in the body and stored in 
bone, with the highest concentrations in the eye and prostate gland. Skin, liver, and muscle also have significant levels, but minimal levels are present in the blood and are decrease with age. The primary function of $\mathrm{Zn}$ is to serve as a component and activator of several enzymatic mechanisms. It is also involved in cellular reproduction and proliferation, the immune system, and electrolyte balance. A Zn deficiency can result in reduced growth, skin lesions, esophageal hyperkeratosis, and reduced lymphocyte concentrations. Intestinal absorption is relatively low and is determined by current $\mathrm{Zn}$ status in the animal (NRC, 1980; McDonald et al., 2002; NRC, 2007).

Manganese is primarily found in the bone, liver, kidney, pancreas, and pituitary gland. It functions to activate several enzymes and is a component of superoxide dismutase, part of the antioxidant system. Additionally, there is evidence of Mn plays a role in lipid and carbohydrate metabolism. In skeletal health, Mn is required for organic compounds in the matrix of bone and synthesis of chondroitin sulfate for cartilage. Retarded growth rate, abnormalities in skeletal development, and impaired reproduction are characteristics of a Mn deficiency. Aside from skin, hair, and feathers, $\mathrm{Mn}$ is not readily stored in the body, as tissues maintain a narrow concentration range for this mineral (NRC, 1980; McDonald et al., 2002; NRC, 2007).

Copper is present in all cells, with the liver being the primary storage site. However, tissue concentrations decline with increasing age. The main function of $\mathrm{Cu}$ is

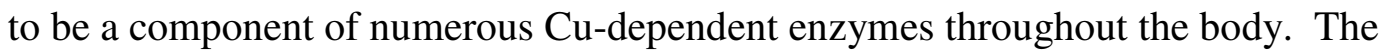
primary role of $\mathrm{Cu}$ is the synthesis of elastic connective tissue through elastin and collagen formation. It is also necessary for iron absorption and release, and is used for 
haemoglobin and melanin synthesis. Copper serves as a component of erythrocuprein, used in oxygen metabolism in plasma proteins and has antioxidant functions as a component of superoxide dismutase. It is also necessary for hair pigmentation. Signs of deficiency include osteochondrosis, epiphysitis, abnormal bone growth, artery rupture, lameness in foals, and loss of skin pigmentation (NRC, 1980; McDonald et al., 2002; NRC, 2007).

Cobalt is widely dispersed throughout the body with high concentrations and accumulation found in the liver, kidney, and bone. It is a component of and is used by microbes in rumen/cecum to synthesize vitamin $B_{12}$, which functions in energy metabolism and red blood cell formation. It also could be involved in enzymatic function. A Co deficiency results in inadequate $\mathrm{B}_{12}$ production with toxicity being improbable, as Co is not readily retained in the body. Signs of deficiency include reduced appetite, weight loss, emaciation, anemia, and the overall appearance of a starving animal. (NRC, 1980; MDonald et al., 2002; NRC, 2007).

Trace minerals are interrelated and should be fed in proper ratios to each other and in the total diet. Focusing on 1 specific mineral can result in a mineral imbalance and eventually a deficiency in another mineral. For example, an excessive level of $\mathrm{Zn}$ or $\mathrm{Cu}$ can lead to an improper $\mathrm{Zn}: \mathrm{Cu}$ ratio. Thus, signs of deficiency in either $\mathrm{Zn}$ or $\mathrm{Cu}$ can appear. Although it is unlikely to induce a Mn toxicity, high levels can inhibit phosphorous digestion and absorption (NRC, 2007).

There are several sources available to supplement trace minerals. Historically, inorganic forms, such as sulfates, have been commonly used in livestock feeds (NRC, 
1980; NRC, 2007). Recently organic, also referred to as chelated or complexed forms, have been created through technological advancement. A chelate is a mineral bound to a polysaccharide, peptide, or specific amino acid, such as lysine or methionine.

Proteinates describe a chelate ligated to an amino acid or peptide. Theoretically, the increased rate of absorption and trace mineral deposition in the body from organic sources is associated with the ease of amino acid complex transport compared to an ionspecific absorption of inorganic sources, such as sulfates (Acda and Chae, 2002; Vieria, 2008). However, trace mineral research relative to source has neglected to support this hypothesis.

The literature remains contradictory on the effect of organic and inorganic forms of trace minerals across multiple livestock species. An organic $\mathrm{Zn}$ source has been documented to improve hoof growth and integrity in dairy cattle and Mn absorption in broilers (Ji et al., 2006; Siciliano-Jones et al., 2008). However, in pigs, growth parameters, digestibility, and retention are not affected by trace mineral type (Case and Carlson, 2002; Buff et al., 2005). Moreover, research on trace mineral bioavailability from different sources in horses is limited and contradictory. When horses were fed oxide, sulfate, or a proteinated chelate (organic) form of $\mathrm{Zn}, \mathrm{Mn}$, and $\mathrm{Cu}$ there was no difference in absorption or retention. For all treatments, absorption of $\mathrm{Zn}$ was higher in the first period of the study suggesting that efficiency of absorption and retention is higher when animals are deficient (Wagner et al., 2005). There also was no difference in the increase in serum $\mathrm{Zn}$ when horses were given a single dose of either $\mathrm{Zn}$ sulfate or the chelated form of $\mathrm{Zn}$. However, both of these had a higher dose-dependent response than 
control horses or those treated with Zn oxide (Wichert et al., 2002). Naile et al. (2005) did not find a consistent improvement in trace mineral digestibility or yearling growth between feeding an inorganic and organic source. Bone mineral concentrations in exercising yearling horses were not different, regardless of trace mineral supplement source. However, a subsequent investigation by the same primary author found a higher digestibility and daily balance of $\mathrm{Cu}$ and $\mathrm{Zn}$ when geldings were consuming sulfated trace minerals as opposed to a chelated source (Baker et al., 2003; Baker et al., 2005). A final study reported the effects of proteinated and inorganic minerals were comparable on growth and skeletal development in horses. However, there could be a benefit in hoof growth when proteinated sources are supplemented (Ott and Johnson, 2001). Miller et al. (2003) reported a higher $\mathrm{Cu}$ daily balance and digestibility, along with a higher $\mathrm{Zn}$ daily balance in yearling stock horses consuming organic trace minerals compared to control and inorganic supplemented yearlings. Thus, a clear benefit of using one form over the other has yet to be elucidated, particularly for the equine species.

In addition to the previous gastric ulcer research on diet, such as concentrate and hay type, there also is preliminary documentation that trace minerals could play a role in ulcer development. In a study on stress-induced gastric ulcers in mice, $\mathrm{Zn}$ status had no effect on ulcer formation. However, $\mathrm{Zn}$-deficient mice did have a reduced healing rate. Thus, it appeared that $\mathrm{Zn}$ had no effect on ulcer development, but a deficiency could delay the healing process (Watanabe et al., 1995). There also is evidence that an organic trace mineral complex could have an effect on ulcer development. A Zn proteinated 
complex reduced intestinal lesions in broilers. This was primarily attributed to the role Zn plays in cellular integrity and repair (Zinpro, 2004). Manganese, $\mathrm{Cu}$, and Co could also play supporting roles in epithelial damage through antioxidant capabilities, as well as enzymatic and immunological functions (NRC, 2007). Therefore, the research opportunities available to ascertain the possible anti-ulcerogenic effect of diet continue to be expansive. 


\section{CHAPTER III}

\section{MATERIALS AND METHODS}

\section{Horses}

Twenty-one Quarter Horse yearlings (15 to18 mo.) owned by the Texas A\&M University Department of Animal Science Horse Center facility in College Station, TX were utilized for this study, which included 11 geldings $(367.3 \pm 9.2 \mathrm{~kg})$ and 10 fillies $(369.5 \pm 9.6 \mathrm{~kg})$. All yearlings were born and raised at the Horse Center facility and had not been transported off the grounds. Prior to initiating the trial, horses were managed on pasture in groups of approximately 10 yearlings and were group fed a $16 \% \mathrm{CP}$ pelleted concentrate (Producers Co-op, Bryan, TX) twice/d. Additionally, they were participating in an undergraduate halter breaking and training class. In compliance with the herd health program at the Texas A\&M facility, horses received appropriate vaccinations and were dewormed prior to initiating the trial. Research was conducted in accordance with Institutional Animal Care and Use Committee (IACUC) guidelines of Texas A\&M University.

\section{Experiment and Treatment Design}

This experiment was designed and analyzed as a $3 \times 3$ factorial with repeated measures, consisting of 3 consecutive 28 -d periods, with a $5 \mathrm{~d}$ diet acclimation between periods. Horses were blocked by initial EGUS score and BW, then randomly assigned to 1 of 3 treatment groups, such that there were 3 groups of 7 horses. Group I, control 
$(\mathrm{CON})$, received no trace mineral supplementation above the inherent levels in the basal grain and hay. Group II (INO) received the basal ration plus $41.6 \mathrm{mg} / \mathrm{kg}$ of BW of an inorganic trace mineral mix, which included $\mathrm{Zn}, \mathrm{Mn}, \mathrm{Cu}$ and $\mathrm{Co}$, as zinc sulfate, manganese sulfate, copper sulfate, and cobalt sulfate (Table 1). Group III (ORG) received the basal ration plus $41.6 \mathrm{mg} / \mathrm{kg}$ of $\mathrm{BW}$ of an organic trace mineral mix, consisting of $\mathrm{Zn}, \mathrm{Mn}, \mathrm{Cu}$, and $\mathrm{Co}$, as $\mathrm{Zn}$ methionine complex, $\mathrm{Mn}$ methionine complex, $\mathrm{Cu}$ lysine, and Co glucoheptonate, respectively (Table 1). Treatment groups were fixed throughout the duration of the trial (i.e., control horses never received inorganic or organic trace mineral supplementation and vice versa). Period was defined by hay type in order to examine the influence of hay source. Period 1 and 3 consisted of feeding coastal Bermuda grass hay (CB) and horses consumed alfalfa hay (ALF) in Period 2.

\section{Diet}

The basal ration included both concentrate and hay. The concentrate consisted of a 14\% CP textured concentrate, specifically formulated for this study (Producers Co-op, Bryan, TX) (Table 1). Horses were individually fed $2.25 \% \mathrm{BW}$, which consisted of $1.25 \%$ of $\mathrm{BW}$ in concentrate, with hay being fed at $1 \%$ of $\mathrm{BW}$. The ration was formulated to meet or exceed NRC recommendations for 18-mo-old horses undergoing light exercise, except for the trace minerals $\mathrm{Zn}, \mathrm{Mn}, \mathrm{Cu}$, and $\mathrm{Co}$, which were not added. The total ration was equally divided with half being fed in the morning (6:00AM) and half in the evening (5:00PM). The inorganic and organic trace mineral supplements were fed according to BW and combined with the concentrate for each horse in mineral 
supplemented treatment groups. Horses were allowed 30 min to consume grain and 2.5 h to consume hay. Refusals were collected, weighed, and recorded for each horse following each feeding to determine intake. Horses were weighed every $7 \mathrm{~d}$, and concentrate, hay, and supplement amounts adjusted accordingly. Body condition scores (BCS) also were assigned at baseline (Period 0) and at the conclusion of each period using a previously described system (Henneke et al., 1983). Three independent appraisers determined BCS for each horse and the average was recorded. In order to maintain consistency, the same individuals were involved in scoring for each period.

Horses were transitioned to the research ration for Period 1 approximately $6 \mathrm{wk}$ prior to initiating the trial to allow adequate diet acclimation for all horses. Between Periods 1 and 2, there were $5 \mathrm{~d}$ of diet acclimation, during which time horses were switched from CB to ALF. This same procedure was replicated between Period 2 and 3 as horses were transitioned from ALF to CB hay. Horses continued to receive their respective trace mineral supplements during the acclimation period.

Concentrate and trace mineral supplements were analyzed for moisture levels and nutrient content (SDK Laboratories, Hutchinson, KS). Both CB and ALF hays also were analyzed for nutrient content (Texas AgriLife Extension Service - Soil, Water, and Forage Testing Laboratory, College Station, TX). Water samples from all sources were analyzed for mineral levels (Cornell University, Ithaca, NY).

Dry matter values were determined for hay samples using a procedure that is standard in an associated Texas A\&M University Department of Animal Science Animal Nutrition Lab. A core sampler was used to collect hay samples from 20 square bales for 
dry matter (DM) determination. Samples were immediately placed in a pre-weighed, brown paper sack and weighed, then placed in a Lindberg/Blue drying oven at $60^{\circ} \mathrm{C}$ for 5 $\mathrm{d}$ to determine partial dry matter. Samples were removed and allowed to equilibrate at room temperature for $8 \mathrm{~h}$. Then, the weight was determined and the sample was placed in a Lindberg/Blue $105^{\circ} \mathrm{C}$ drying oven for $18 \mathrm{~h}$. Upon removal, the sample was placed in a desiccator for $20 \mathrm{~min}$, after which a final weight was taken. Final dry matter values were determined by multiplying partial DM and post- $105^{\circ} \mathrm{C} \mathrm{DM}$.

Table 1. Analysis of feed sources used in diet formulation (100\% DM basis)

\begin{tabular}{lcccccc}
\hline \hline & \multicolumn{7}{c}{ Feed Source } \\
\cline { 2 - 7 } Nutrient & Grain & Period 1 CB & ALF & Period 3 CB & INO & ORG \\
\hline CP, $(\%)$ & 13.93 & 11.60 & 22.50 & 14.10 & -- & -- \\
Dig CP, $(\%)$ & -- & 8.20 & 18.60 & 10.50 & -- & -- \\
ADF, $(\%)$ & 6.59 & 35.40 & 28.30 & 34.00 & -- & -- \\
TDN, (\%) & 78.71 & 66.00 & 75.80 & 68.00 & -- & -- \\
DE, (Mcal/kg) & 4.01 & 2.91 & 3.35 & 3.00 & -- & -- \\
Moisture, $(\%)$ & 13.05 & 15.06 & 14.13 & 13.92 & -- & -- \\
P, $(\%)$ & 0.46 & 0.16 & 0.26 & 0.18 & 0.03 & 0.04 \\
K, $(\%)$ & 0.97 & 1.14 & 2.42 & 1.23 & 0.12 & 0.16 \\
Ca, $(\%)$ & 0.97 & 0.53 & 2.05 & 0.54 & 30.64 & 23.34 \\
Mg, (\%) & 0.17 & 0.21 & 0.47 & 0.24 & 0.27 & 0.16 \\
Na, ppm & 2233 & 1369 & 1841 & 1967 & 900 & 8900 \\
Fe, ppm & 187 & 88 & 162 & 62 & 1200 & 4100 \\
S, ppm & 2633 & -- & -- & -- & 19900 & 37500 \\
Zn, ppm & 48 & 22 & 31 & 25 & 21100 & 22400 \\
Mn, ppm & 44 & 84 & 58 & 77 & 18700 & 21200 \\
Cu, ppm & 13 & 5 & 7 & 8 & 8610 & 7860 \\
Co, ppm & 0.46 & -- & -- & -- & 123 & 252 \\
\hline
\end{tabular}

During the first 2 periods, horses were separated into assigned, individual, $3 \times 3 \mathrm{~m}$ concrete-floored stalls to consume each meal. This allowed investigators to manage 
horse consumption, as well as accurately collect refusals. Feeding stalls also were sectioned by treatment group to prevent trace mineral cross-contamination. Water from the same source was available ad libitum in each feeding stall for every meal.

In Period 3, horses were housed in individual stalls, which is where they also consumed their meals. Refusals continued to be collected after each feeding. Water buckets were filled before and after each meal.

\section{Endoscopic Examination}

Gastric ulcers were viewed, diagnosed, and scored 4 times throughout the trail via endoscopic examination. Scores were determined prior to initiating the trial (baseline) and at the conclusion of Periods 1, 2, and 3. In Periods 1 and 2, horses were placed in individual, concrete feeding stalls and fasted for $18 \mathrm{~h}$ prior to endoscopy, except for water, which was removed $1.5 \mathrm{~h}$ pre-examination. Fasting allowed for an unobstructed view of the non-glandular and glandular squamous epithelial mucosa and more effective ulcer score determination. Horses were monitored during fasting and feces collected to prevent coprophagy, as fecal matter would interfere with complete visualization of the stomach lining. In Period 3, horses were already in individual stalls, which were bedded with pine shavings. Consequently, yearlings were muzzled to prevent both coprophagy and consumption of shavings. As in Periods 1 and 2, horses were fasted for $18 \mathrm{~h}$. During this time, they were constantly monitored and hand watered every $2 \mathrm{~h}$, until $1.5 \mathrm{~h}$ pre-endoscopy. 
Horses were placed in stocks and mildly sedated with 200 to $250 \mathrm{mg}$ of xylazine (approximately $0.50 \mathrm{mg} / \mathrm{kg}$ ). A humane twitch was used for restraint, which facilitated passage of a lubricated 1-m-long, 1.65-cm-diameter nasoesophageal tube. This tube provided protection against intrapharyngeal retroflextion for the GIF-3-m flexible endoscope (Olympus, Tokyo, Japan). The endoscope was passed through the tube into the stomach via the esophagus. As the scope entered the cardia, the stomach was inflated to increase the visible surface area for accurate evaluation. Limited water was used to rinse away debris or digesta to minimize aqueous obstruction of the intragastric lining. The squamous mucosa was viewed on a screen and ulcers assigned a score of 0 to 4 by an equine internist, blinded to treatments, using a modified version of the Equine Gastric Ulcer Council's (EGUC) recommended scoring system (Table 2). The scoring system was familiar to the internist and had previously been used by investigators in this laboratory (Merritt, 2003; Lybbert, 2007). Modification of the scoring system included altering a grade 2 ulcer from "small, single or multi-focal erosions or ulcers" to "small, single or multi-focal, non-bleeding erosions or ulcers.”. Additionally, the grade 3 description stating "large, single or multi-focal ulcers or extensive erosions and sloughing" was revised to represent "large, single or multi-focal erosions or ulcers; or any actively bleeding ulcer." These modifications were made in an attempt to provide more objectivity for the scoring system and ulcer severity assessment under research conditions. Glandular ulcers were counted, recorded, and assigned a score separately from non-glandular ulcers. 
The examination also was recorded on a VHS tape and at least 4 pictures were taken of pertinent views for each horse. Upon completion of the gastroscopic examination, the stomach was deflated by aspiration to prevent discomfort from gas distension, and horses were returned to their respective dry lot pens and monitored.

Table 2. Modified EGUC scoring system used to evaluate gastric ulcers in yearling horses

\begin{tabular}{ll}
\hline \hline Score & Description \\
\hline 0 & Epithelium is intact throughout; no hyperemia or hyperkeratosis \\
1 & Mucosa is intact, but there are areas of hyperemia and hyperkeratosis \\
2 & Small, single or multi-focal, non-bleeding erosions or ulcers \\
3 & Large, single or multi-focal, erosions or ulcers; or any actively bleeding ulcer \\
4 & Extensive ulcers, with areas of deep submucosal penetration \\
\hline
\end{tabular}

When all horses had been evaluated and returned from sedation to normal behavior, about 30 min after the final examination, yearlings were placed in individual feeding stalls and offered hay. After allowing the horses $30 \mathrm{~min}$ to consume hay, they were fed one-half of their normal morning grain ration, including respective trace mineral supplementation. All horses received normal rations within $24 \mathrm{~h}$ of endoscopic examination. 


\section{Housing}

In Periods 1 and 2, the yearlings were housed in 3 similar dry lot pens $(22.50 \mathrm{x}$ $15.39 \mathrm{~m})$ at the Texas A\&M University Horse Center, in order to restrict nutrient intake to that of the research diet. Horses were housed by treatment group, such that there were 2 pens of 7 and 1 pen of 6 . Due to the fact a filly utilized in the study had been purchased prior to the trial, arrangements were made with owners to house her individually in a dry lot pen adjacent to the other yearlings. Water tanks in each pen were filled during each feeding shift to allow ad libitum water consumption.

Period 3 coincided with the commencement of fall classes at Texas A\&M University. Thus, yearlings were transferred from the Texas A\&M University Horse Center to the Texas A\&M University Freeman Equestrian Center (approximately 8.05 $\mathrm{km}$ ) in order to participate in an undergraduate breaking and training laboratory. Horses were individually stalled, with herd mates visually accessible across the barn aisle. These 3.66 x $3.66 \mathrm{~m}$ stalls also were bedded with pine shavings.

\section{Exercise}

In Periods 1 and 2, horses were exercised $3 \mathrm{~d} /$ wk on a mechanical horseexerciser. The exercise regimen included $20 \mathrm{~min}$ at $2.9 \mathrm{~m} / \mathrm{s}$ (long trot), followed by a 5 min cool down at $1 \mathrm{~m} / \mathrm{s}$ (walk). The exerciser contained 6 free-stall compartments; therefore, all treatment groups were equally represented in each 25-min exercise session. Since exercise was conducted in mid-afternoon, directly prior to the evening meal, horses were on a rotational schedule to determine exercise order. This prevented 
yearlings from being exercised at the same time each day, which also eliminated the possibility of the same individuals consistently being in the last exercise session prior to the evening meal.

Because horses were moved to Freeman Arena in order to participate in an undergraduate breaking and training laboratory in Period 3, the exercise regimen was modified. Ideally, all horses would have been involved in class activities and subjected to identical work-outs. However, there were only 9 students enrolled in the class. Therefore, the additional 13 horses were exercised outside of class by investigators, along with fellow graduate students and undergraduate volunteers. The primary form of exercise in the breaking and training laboratory was lunging for approximately $15 \mathrm{~min}$. Therefore, additional horses were longed for $15 \mathrm{~min} 3 \mathrm{~d} / \mathrm{wk}$, in order to mimic in-class exercise. The remaining $2 \mathrm{~d} / \mathrm{wk}$, they were turned out in pairs, within treatment groups, for free exercise in $13.72 \mathrm{~m}$ diameter round pens for $45 \mathrm{~min}$. In order to account for the possible ulcerogenic effect of being involved in a class atmosphere, exercise groups were reversed mid-way through the period. Horses participating in class were longed 3 $\mathrm{d} /$ wk and turned out $2 \mathrm{~d} / \mathrm{wk}$, as described above, while horses previously worked outside of class were assigned to an undergraduate student. All horses also were exposed to a saddle and saddle pad by undergraduate and graduate students during the final $3 \mathrm{~d}$ of their "in-class" experience. 


\section{Transportation}

In cooperation with another research trial and in order to attempt to induce additional stress, horses were transported for $6 \mathrm{~h}$ in a single deck semi-trailer $5 \mathrm{~d}$ prior to the end of each period. Because of trailer space allocations, horses were divided into 2 groups, with treatment groups being equally represented, and transported on 2 consecutive d. Blood samples also were taken before, after, and at 2-h intervals during hauling. Endoscopies were conducted 5 d post-transportation to determine ulcer score. Horses were not exercised between transportation and endoscopic examination.

\section{Statistical Analysis}

Data were analyzed as repeated measures using the mixed model procedures of SAS (SAS Institute, version 9.2, Cary, NC, USA). The model included fixed effects of treatment, period, and treatment by period interaction. The random effect was horse nested within treatment group. A $P$-value $<0.05$ was considered significant. When significant effects were observed, means were separated with a protected pairwise t-test.

After primary analysis, there was an interest to observe individual treatment group effects, independently of one another. Therefore, post hoc analyses were conducted using the model described above with slight modification, which resulted in each treatment group and period being analyzed completely individually, without respect to additional periods and treatments. A $P$-value $<0.05$ continued to be the level of significance. 
Glandular ulcers were rare; therefore, statistical analyses in the results only represent non-glandular ulcers. 


\section{CHAPTER IV}

RESULTS

\section{Ulcer Score}

At baseline, 16 horses ( $76 \%$ ) had ulcers, 7 of these horses scored a 2 and 9 horses scored a 3 (Table 3). Hyperkeratosis was present in an additional 3 horses and 2 individuals $(10 \%)$ scored a 0 . At the conclusion of Period 1, 15 horses $(71 \%)$ had ulcers, an additional horse had hyperkeratosis, and 5 (24\%) scored a 0. All 15 horses with ulcers in Period 1 scored a 2. There were 8 horses (38\%) with ulcers at the end of Period 2, all receiving a score of 2 . Hyperkeratosis was observed in an additional 5 horses, with 8 individuals (38\%) scored a 0 in Period 2. Finally, 14 horses $(67 \%)$ had ulcers at the conclusion of Period 3, with all being a score 2. An additional 3 horses (14\%) were scored a 1 for hyperkeratosis. There were 4 individuals (19\%) that scored a 0 . The proportion of yearlings that had ulcers (ulcer score $\geq 2$ ) or did not have ulcers (ulcer score $<2$ ) in each period across all treatment groups is presented in Figure 1.

Table 3. Number of horses assigned to each score in modified EGUC scoring system across all treatment groups for each period

\begin{tabular}{ccccc}
\hline Score & Baseline & Period 1 & Period 2 & Period 3 \\
\hline 0 & 2 & 5 & 8 & 4 \\
1 & 3 & 1 & 5 & 3 \\
2 & 7 & 15 & 8 & 14 \\
3 & 9 & 0 & 0 & 0 \\
4 & 0 & 0 & 0 & 0 \\
\hline
\end{tabular}




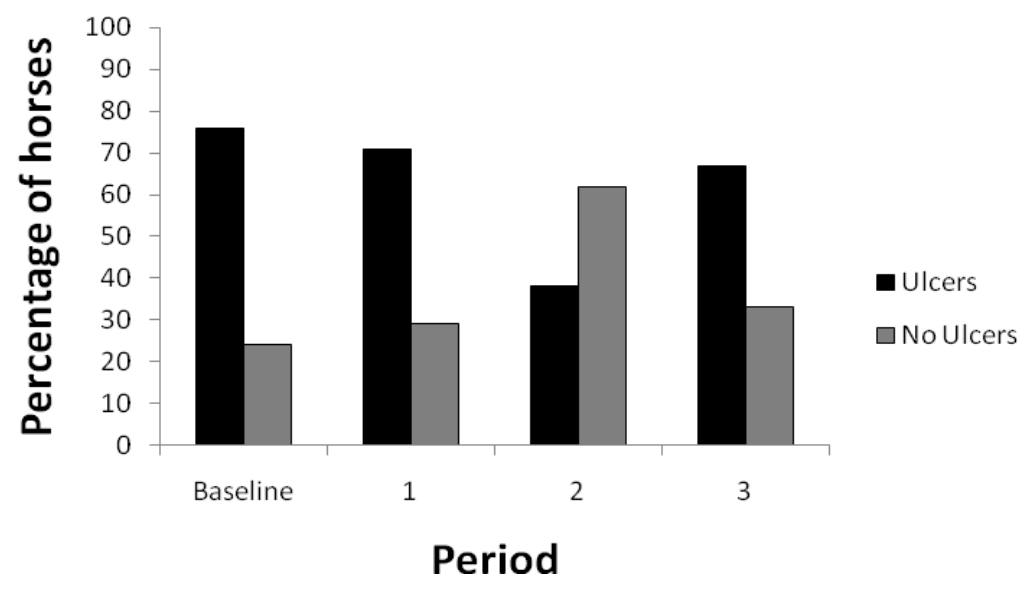

Figure 1. Percentage of yearling horses with ulcers or without ulcers in each period.

Glandular ulcers were evaluated, counted, and scored separately from nonglandular ulcers. Because glandular ulcers are typically rare in comparison to the appearance of non-glandular but can be of clinical significance, it is important to report the prevalence of ulceration in this region, even though statistical analysis of these data were not significant and are not presented. Glandular ulcers were present in 2 horses at the end of Period 1 and 1 horse at the conclusion of Period 3, all of which scored a 2. However, no glandular ulcers were detected at baseline or in Period 2. Furthermore, analyzing the entire trial, the glandular ulcers were evenly distributed among the treatment groups, with an ORG and INO each being represented in Period 1 and the CON having a horse with a glandular ulcer in Period 3.

Baseline ulcer scores were not different between treatment groups $(P=0.84)$, so horses were adequately blocked by treatment group (Table 4). There was no difference in ulcer score between the treatments in any period, resulting in no overall treatment effect $(P=0.60)$ (Table 4$)$ and no period by treatment interaction $(P=0.46)$ (Figure 2$)$. 
Table 4. Ulcer scores ${ }^{1}$ of yearling horses fed no added trace mineral $(\mathrm{CON})$, inorganic trace mineral (INO), or organic trace mineral (ORG)

\begin{tabular}{|c|c|c|c|c|c|c|}
\hline \multirow[b]{2}{*}{ Item } & \multicolumn{4}{|c|}{ Period } & \multirow[b]{2}{*}{$\mathrm{SEM}^{2}$} & \multirow[b]{2}{*}{$P$-value ${ }^{3}$} \\
\hline & Baseline & 1 & 2 & 3 & & \\
\hline Treatment & & & & & & 0.60 \\
\hline $\mathrm{CON}$ & 2.3 & 1.9 & 1.3 & 1.1 & 0.31 & \\
\hline INO & 2.0 & 1.4 & 1.1 & 1.6 & 0.35 & 0.46 \\
\hline ORG & 2.0 & 1.1 & 0.6 & 1.7 & 0.36 & \\
\hline Overall $^{4}$ & $2.1^{\mathrm{a}}$ & $1.5^{\mathrm{b}}$ & $1.0^{\mathrm{b}}$ & $1.5^{\mathrm{b}}$ & 0.20 & $<0.01$ \\
\hline
\end{tabular}

${ }^{\mathrm{a}, \mathrm{b}}$ Within a row, means without a common superscript differ $(P<0.05)$.

${ }^{1}$ Least squares means for individual treatment groups in each period.

${ }^{2} \mathrm{SEM}=$ standard error of least squares means; treatment groups analyzed independently $(\mathrm{n}=3)$.

${ }^{3} P$-value for the effect of treatment, treatment $\mathrm{x}$ period interaction, and period, respectively on ulcer score.

${ }^{4}$ Overall = Least square means across all treatment groups $(\mathrm{n}=21)$ within each period $(n=4)$.

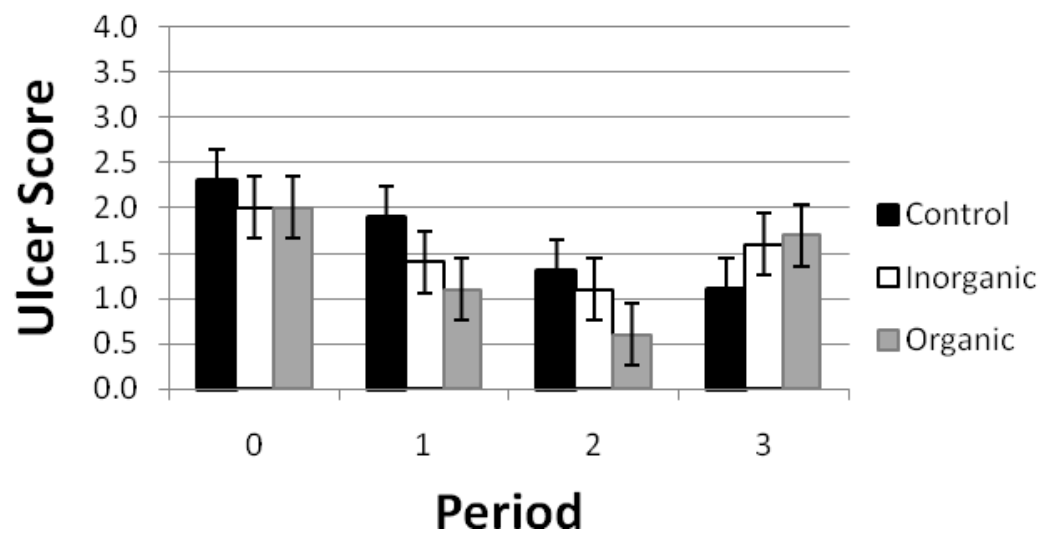

Figure 2. Mean EGUS scores of yearling horses in consuming no trace mineral (Control), inorganic trace mineral (Inorganic), or organic trace mineral (Organic) by period. 
There was a significant period effect $(P<0.01)$ (Figure 3$)$. Ulcer scores at the conclusion of Periods 1, 2, and 3 were lower than baseline (Table 4). There also was a trendency $(P=0.06)$ for Period 2 ulcer scores to be lower than Period 1 and Period 3. However, mean ulcer scores for Periods 1 and 3 were equal $(P=1.0)$.

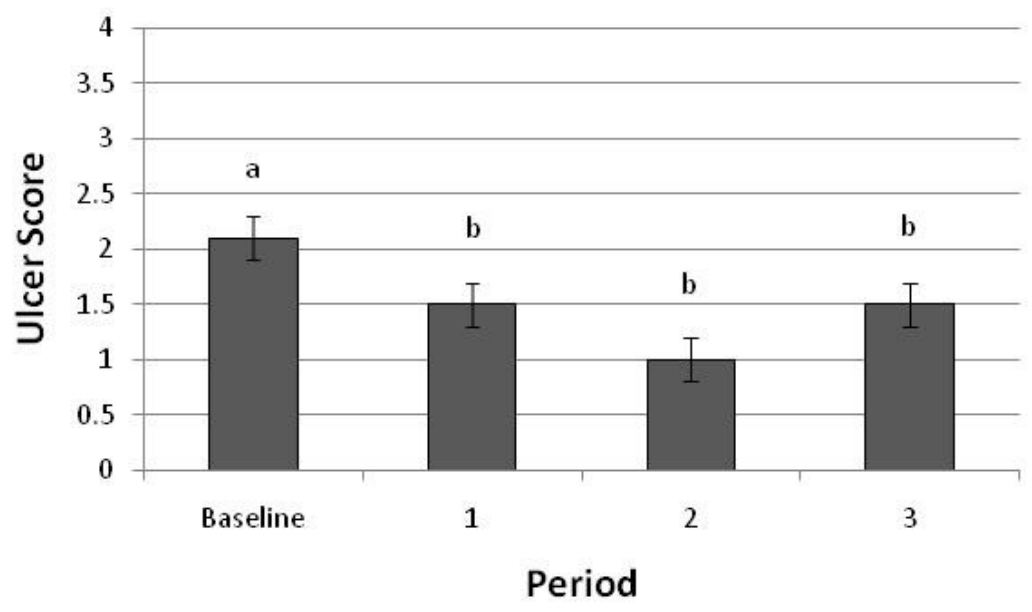

Figure 3. Mean EGUS scores of yearling horses for period across all treatments consuming no, inorganic, or organic trace mineral. ${ }^{\mathrm{a}, \mathrm{b}}$ Periods without a common superscript are different $(P<0.05)$.

There was no gender effect on ulcer score $(P=0.45)$ nor a gender by treatment interaction $(P=0.68)$.

The change in ulcer score between periods also was calculated. There was no overall effect of treatment $(P=0.51)$ and no period by treatment interaction $(P=0.28)$ (Figure 4). There was a period effect $(P<0.01)$ (Table 5). The change in ulcer score between Baseline and Period 1 was significantly different from the change in ulcer score 
between Periods 2 and 3. Ulcer scores decreased from baseline examinations to endoscopies at the end of Period 1, but increased between endoscopic examinations for Periods 2 and 3. The change in ulcer score from Period 1 to Period 2 was also decreased and was different from the overall increase in score between Periods 2 and 3. The magnitude of decline in ulcer score between baseline to Period 1 compared to Period 1 to Period 2 was not different $(P=0.73)$.

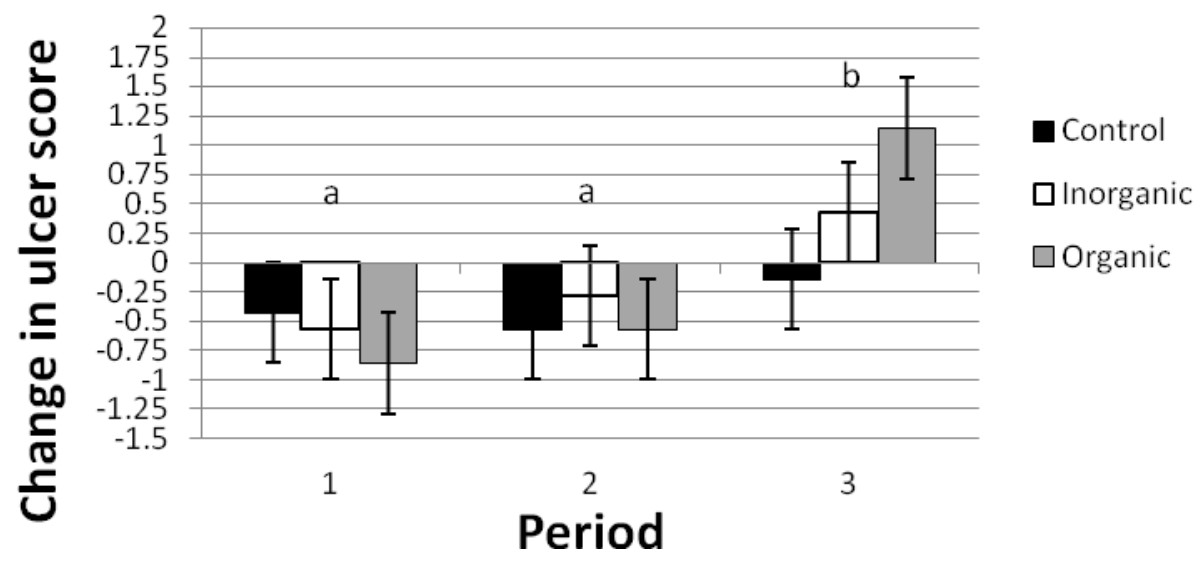

Figure 4. Change in ulcer score values between periods for yearling horses consuming no trace mineral (Control), inorganic trace mineral (Inorganic), or organic trace mineral (Organic) in each period.

${ }^{\mathrm{a}, \mathrm{b}}$ Periods without a common superscript are different $(P<0.05)$. 
Table 5. Change in ulcer scores ${ }^{1}$ in yearling horses being fed no trace mineral supplement $(\mathrm{CON})$, inorganic trace mineral (INO), or organic trace mineral (ORG)

\begin{tabular}{|c|c|c|c|c|c|}
\hline \multirow[b]{2}{*}{ Item } & \multicolumn{3}{|c|}{ Period } & \multirow[b]{2}{*}{$\mathrm{SEM}^{3}$} & \multirow[b]{2}{*}{$P$-Value ${ }^{4}$} \\
\hline & $1^{2}$ & $2^{2}$ & $3^{2}$ & & \\
\hline Treatment & & & & & $\overline{0.51}$ \\
\hline $\mathrm{CON}$ & -0.43 & -0.57 & -0.14 & 0.44 & \\
\hline INO & -0.57 & -0.29 & 0.43 & 0.43 & 0.28 \\
\hline ORG & -0.86 & -0.57 & 1.14 & 0.41 & \\
\hline Overall $^{5}$ & $-0.62^{a}$ & $-0.48^{a}$ & $0.48^{\mathrm{b}}$ & 0.25 & $<0.01$ \\
\hline
\end{tabular}

${ }^{\mathrm{a}, \mathrm{b}}$ Within a row, means without common superscripts are different $(P<0.05)$.

${ }^{1}$ Least squares means of the change between ulcer score values in subsequent periods.

${ }^{2}$ Ulcer score change from Period 0 to 1 (1), Period 1 to 2 (2), and Period 2 to 3 (3).

${ }^{3} \mathrm{SEM}=$ standard error of least squares means; treatment groups analyzed independently $(\mathrm{n}=3)$.

${ }^{4} P$-value for the effects of treatment, treatment by period interaction, and period, respectively for change in ulcer score.

${ }^{5}$ Overall $=$ least squares means of the change in ulcer score across all treatment groups $(n=21)$ between the periods $(n=3)$.

There was no effect of gender on change in ulcer score between periods $(P=$

$0.26)$ and no gender by treatment interaction $(P=0.61)$.

\section{Grain, Hay, and Supplement Intake}

Grain. Average daily intake (ADI) of grain did not differ by treatment group irrespective of period $(P=0.97)$. However, there was an increase in grain intake with each subsequent period $(\mathrm{P}<0.0001)$ (Table 6). Moreover, when calculated on a percentage body weight as intake/kg, there is only a difference in ADI of grain between Periods 1 and $2(P<0.01)$.

Hay. There was not a treatment effect of ADI of hay $(P=0.98)$, but there was a period effect $(P<0.0001)$ between Periods 1 and 2 and Periods 2 and 3, but not Periods 
1 and 3 (Table 6). Horses consumed more hay in Period 2 than in Periods 1 or 3. They were consuming ALF in Period 2, while being fed CB in Periods 1 and 3. When analyzing hay intake per $\mathrm{kg}$ of $\mathrm{BW}$, there was a period effect with horses consuming a higher percentage of their BW in Periods 1 and 2 than in Period 3. However, Period 1 and 2 were not different, with the values for ADI of hay on a percentage BW for Periods 1, 2, and 3 being $0.982 \%, 0.996 \%$, and $0.900 \%$ respectively. Subjectively, horses more readily consumed ALF. Total hay refusals collected for Period 1, 2, and 3 were $132 \mathrm{~kg}$, $38 \mathrm{~kg}$, and $270 \mathrm{~kg}$, respectively. Furthermore, mean hay refusal per head for Periods 1 , 2, and 3 was $5.2 \mathrm{~kg}, 1.7 \mathrm{~kg}$, and $13.0 \mathrm{~kg}$, respectively.

Supplement. The ADI of supplement differed by treatment group, with the INO and ORG being higher than the CON $(P<0.01)$. This is obvious as the CON group received no supplementation; the supplement intakes of the INO and ORG treatment groups were not different. There was a period effect $(P<0.01)$ as ADI of supplemental trace minerals was higher in every period. This can be attributed to their weight gains, as supplementation level was based on body weight.

Total DMI. The total average daily DMI did not have a treatment effect $(P=$ 0.99), but did have a period effect $(P<0.0001)$ (Table 6). Periods 2 and 3 were not different $(P=0.61)$, but both were significantly higher than Period $1(P<0.0001)$. 
Table 6. Mean intake ${ }^{1}$ of grain, hay, and supplement for all periods in yearling horses consuming no trace minerals (CON), inorganic trace minerals (INO), or organic trace minerals (ORG)

\begin{tabular}{|c|c|c|c|c|c|c|c|c|c|c|c|}
\hline \multirow[b]{3}{*}{ Item } & \multicolumn{9}{|c|}{ 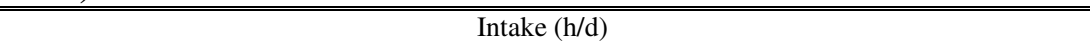 } & \multirow[b]{3}{*}{$\mathrm{SEM}^{2}$} & \multirow[b]{3}{*}{$\mathrm{TxP}^{3}$} \\
\hline & \multicolumn{3}{|c|}{ Period 1} & \multicolumn{3}{|c|}{ Period 2} & \multicolumn{3}{|c|}{ Period 3} & & \\
\hline & $\mathrm{CON}$ & INO & ORG & $\mathrm{CON}$ & INO & ORG & $\mathrm{CON}$ & INO & ORG & & \\
\hline Grain, $\mathrm{kg}$ & $4.11^{\mathrm{a}}$ & $4.20^{\mathrm{a}}$ & $4.14^{\mathrm{a}}$ & $4.22^{\mathrm{b}}$ & $4.27^{b}$ & $4.23^{b}$ & $4.45^{\mathrm{c}}$ & $4.45^{\mathrm{c}}$ & $4.49^{\mathrm{c}}$ & 0.14 & 0.87 \\
\hline Hay, kg & $3.14^{\mathrm{a}}$ & $3.16^{\mathrm{a}}$ & $3.06^{\mathrm{a}}$ & $3.32^{\mathrm{b}}$ & $3.33^{\mathrm{b}}$ & $3.39^{\mathrm{b}}$ & $3.19^{\mathrm{a}}$ & $3.14^{\mathrm{a}}$ & $3.13^{\mathrm{a}}$ & 0.11 & 0.56 \\
\hline Suppl., g & $0.00^{\mathrm{a}}$ & $15.82^{\mathrm{b}}$ & $15.95^{\mathrm{b}}$ & $0.00^{\mathrm{a}}$ & $16.47^{\mathrm{c}}$ & $16.67^{\mathrm{c}}$ & $0.00^{\mathrm{a}}$ & $17.03^{\mathrm{d}}$ & $17.25^{\mathrm{d}}$ & 0.40 & $<0.0001$ \\
\hline Total, ${ }^{4} \mathrm{~kg}$ & $7.25^{\mathrm{a}}$ & $7.35^{\mathrm{a}}$ & $7.20^{\mathrm{a}}$ & $7.54^{\mathrm{b}}$ & $7.60^{\mathrm{b}}$ & $7.62^{\mathrm{b}}$ & $7.64^{\mathrm{b}}$ & $7.59^{\mathrm{b}}$ & $7.62^{\mathrm{b}}$ & 0.23 & 0.61 \\
\hline \multicolumn{12}{|c|}{$\overline{\mathrm{a}, \mathrm{b}, \mathrm{c}}$ Within a row, means without a common superscript are different $(P<0.05)$} \\
\hline \multicolumn{12}{|c|}{${ }^{1}$ Least squares means for intake of grain, hay, supplement, and total feed. } \\
\hline \multicolumn{12}{|c|}{$\begin{array}{l}{ }^{2} \mathrm{SEM}=\text { standard error of means for the period by treatment interaction for each feed } \\
\text { component. }\end{array}$} \\
\hline \multicolumn{12}{|c|}{${ }^{3} \mathrm{TxP}=P$-value for the treatment by period interaction for each feed component. } \\
\hline
\end{tabular}

Mean daily nutrient intakes by treatment group for hay and concentrate are provided in Tables 7, 8, and 9.

Table 7. Period 1 mean daily nutrient intake from hay and grain in yearling horses consuming no $(\mathrm{CON})$, inorganic (INO), or organic $(\mathrm{ORG})$ trace minerals $(100 \% \mathrm{DM}$ basis)

\begin{tabular}{|c|c|c|c|c|c|c|}
\hline \multirow[b]{3}{*}{ Nutrient } & \multicolumn{6}{|c|}{ Treatment } \\
\hline & \multicolumn{2}{|c|}{$\mathrm{CON}$} & \multicolumn{2}{|c|}{ INO } & \multicolumn{2}{|c|}{ ORG } \\
\hline & (g) & $(\mathrm{g} / \mathrm{kg}) \mathrm{BW}$ & (g) & $(\mathrm{g} / \mathrm{kg}) \mathrm{BW}$ & (g) & $(\mathrm{g} / \mathrm{kg}) \mathrm{BW}$ \\
\hline Protein & 936.56 & 2.55 & 950.53 & 2.53 & 931.64 & 2.46 \\
\hline $\mathrm{ADF}$ & 1382.73 & 3.76 & 1393.82 & 3.71 & 1356.42 & 3.58 \\
\hline TDN & 5306.26 & 14.42 & 5385.23 & 14.34 & 5278.07 & 13.93 \\
\hline DE (Mcal) & 25.62 & 0.0696 & 26.01 & 0.0693 & 25.51 & 0.0673 \\
\hline Phosphorus & 23.92 & 0.0650 & 24.35 & 0.0648 & 23.94 & 0.0632 \\
\hline Potassium & 78.12 & 0.2123 & 79.19 & 0.2109 & 75.53 & 0.2046 \\
\hline Calcium & 56.49 & 0.1535 & 57.42 & 0.1529 & 56.37 & 0.1487 \\
\hline Magnesium & 13.58 & 0.0369 & 13.76 & 0.0366 & 13.46 & 0.0355 \\
\hline Sodium & 13.47 & 0.0366 & 13.69 & 0.0365 & 13.43 & 0.0354 \\
\hline Iron & 1.05 & 0.0028 & 1.06 & 0.0028 & 1.04 & 0.0028 \\
\hline Sulfur & 10.82 & 0.0294 & 11.05 & 0.0294 & 10.90 & 0.0288 \\
\hline
\end{tabular}


Table 8. Period 2 mean daily nutrient intake from hay and grain in yearling horses consuming no (CON), inorganic (INO), or organic (ORG) trace minerals (100\% DM basis)

\begin{tabular}{|c|c|c|c|c|c|c|}
\hline \multirow[b]{3}{*}{ Nutrient } & \multicolumn{6}{|c|}{ Treatment } \\
\hline & \multicolumn{2}{|c|}{$\mathrm{CON}$} & \multicolumn{2}{|c|}{ INO } & \multicolumn{2}{|c|}{ ORG } \\
\hline & $(\mathrm{g})$ & $(\mathrm{g} / \mathrm{kg}) \mathrm{BW}$ & $(\mathrm{g})$ & $(\mathrm{g} / \mathrm{kg}) \mathrm{BW}$ & (g) & $(\mathrm{g} / \mathrm{kg}) \mathrm{BW}$ \\
\hline Protein & 1335.51 & 3.47 & 1344.14 & 3.43 & 1351.42 & 3.41 \\
\hline $\mathrm{ADF}$ & 1217.86 & 3.16 & 1223.02 & 3.12 & 1237.87 & 3.12 \\
\hline TDN & 5842.19 & 15.16 & 5887.86 & 15.01 & 5895.79 & 14.87 \\
\hline DE (Mcal) & 28.07 & 0.0729 & 28.30 & 0.0721 & 28.31 & 0.0714 \\
\hline Phosphorus & 28.07 & 0.0728 & 28.32 & 0.0722 & 28.25 & 0.0713 \\
\hline Potassium & 123.85 & 0.3214 & 124.54 & 0.3175 & 125.57 & 0.3168 \\
\hline Calcium & 109.04 & 0.2830 & 109.67 & 0.2796 & 110.49 & 0.2787 \\
\hline Magnesium & 22.78 & 0.0591 & 22.90 & 0.0584 & 23.12 & 0.0583 \\
\hline Sodium & 15.55 & 0.0404 & 15.68 & 0.0400 & 15.68 & 0.0396 \\
\hline Iron & 1.33 & 0.0035 & 1.34 & 0.0034 & 1.34 & 0.0034 \\
\hline Sulfur & 11.13 & 0.0289 & 11.27 & 0.0287 & 11.13 & 0.0281 \\
\hline
\end{tabular}

Table 9. Period 3 mean daily nutrient intake from hay and grain in yearling horses consuming no (CON), inorganic (INO), or organic (ORG) trace minerals (100\% DM basis)

\begin{tabular}{|c|c|c|c|c|c|c|}
\hline \multirow[b]{3}{*}{ Nutrient } & \multicolumn{6}{|c|}{ Treatment } \\
\hline & \multicolumn{2}{|c|}{$\mathrm{CON}$} & \multicolumn{2}{|c|}{ INO } & \multicolumn{2}{|c|}{ ORG } \\
\hline & (g) & $(\mathrm{g} / \mathrm{kg}) \mathrm{BW}$ & (g) & $(\mathrm{g} / \mathrm{kg}) \mathrm{BW}$ & (g) & $(\mathrm{g} / \mathrm{kg}) \mathrm{BW}$ \\
\hline Protein & 1069.36 & 2.64 & 1062.84 & 2.62 & 1063.71 & 2.59 \\
\hline $\mathrm{ADF}$ & 1376.60 & 3.39 & 1360.89 & 3.35 & 1358.27 & 3.31 \\
\hline TDN & 5670.49 & 13.97 & 5639.06 & 13.90 & 5645.23 & 13.74 \\
\hline DE (Mcal) & 27.41 & 0.0675 & 27.27 & 0.0672 & 27.31 & 0.0665 \\
\hline Phosphorus & 26.21 & 0.0646 & 26.13 & 0.0644 & 26.19 & 0.0638 \\
\hline Potassium & 85.04 & 0.3027 & 84.47 & 0.3028 & 84.52 & 0.2995 \\
\hline Calcium & 60.39 & 0.1488 & 60.14 & 0.1482 & 60.25 & 0.1467 \\
\hline Magnesium & 15.21 & 0.0375 & 15.10 & 0.0372 & 15.11 & 0.0368 \\
\hline Sodium & 16.21 & 0.0399 & 16.12 & 0.0397 & 16.14 & 0.0393 \\
\hline Iron & 1.03 & 0.0025 & 1.03 & 0.0025 & 1.03 & 0.0025 \\
\hline Sulfur & 11.72 & 0.0289 & 11.72 & 0.0289 & 11.77 & 0.0286 \\
\hline
\end{tabular}

\section{Trace Mineral Intake}

The mineral intake from the grain only had a period effect $(P<0.0001)$, as the grain formulation was not manipulated through the study. Thus, the only adjustment in 
intake was due to increasing body weight, which was the basis for grain amounts offered. There was a period effect $(P<0.0001)$ for ADI of trace minerals for the hay as well. However, this difference is not based solely on change in body weight. Period was determined by hay type, as each period had a different hay source. All 3 hay sources did not contain equal levels of the trace minerals under investigation, which resulted in differences. For $\mathrm{Zn}$, all 3 periods were different $(P<0.0001)$, with ALF having the highest intake, followed by the $\mathrm{CB}$ in Period 3, and finally the $\mathrm{CB}$ hay in Period 1. There was also a difference in hay Mn intake in every period $(P<0.001)$, with the opposite concentration rank as found in ALF. Period $1 \mathrm{CB}$ hay was the highest followed by Period $3 \mathrm{CB}$, then ALF. The intakes of $\mathrm{Cu}$ also were different between all three periods $(P<0.0001)$, with Period 3 CB hay having the highest concentration, followed by ALF and Period $1 \mathrm{CB}$, respectively. None of the hay types contained Co.

Trace mineral intake was primarily influenced by treatment group, as horses receiving INO or ORG were provided with levels greater than inherently available in their basal ration. The INO and ORG supplements also were different in concentration for each mineral. The ORG supplement contained higher levels of $\mathrm{Zn}, \mathrm{Mn}$, and Co. The INO supplement was higher in $\mathrm{Cu}$ than the ORG. The specific mineral intake from grain, hay, and supplement are provided below (Tables 10-12). 
Table 10. Average daily intake ${ }^{1}$ of zinc, manganese, copper, and cobalt from grain fed to yearling horses supplemented with no trace mineral (CON), inorganic minerals (INO), or organic minerals $(\mathrm{ORG})(\mathrm{mg} / \mathrm{hd} / \mathrm{d})$

\begin{tabular}{|c|c|c|c|c|c|}
\hline \multirow[b]{2}{*}{ Trace Mineral } & \multicolumn{3}{|c|}{ Period } & \multirow[b]{2}{*}{ SEM $^{3}$} & \multirow[b]{2}{*}{$P$-value ${ }^{4}$} \\
\hline & 1 & 2 & 3 & & \\
\hline \multicolumn{5}{|l|}{ Zinc } & \multirow[t]{2}{*}{0.97} \\
\hline $\mathrm{CON}$ & 196.5 & 202.0 & 212.9 & 7.43 & \\
\hline INO & 200.7 & 204.5 & 212.8 & 6.21 & \multirow[t]{2}{*}{0.87} \\
\hline ORG & 198.1 & 202.3 & 214.7 & 6.25 & \\
\hline Overall $^{2}$ & $198.4^{\mathrm{a}}$ & $202.9^{\mathrm{b}}$ & $213.5^{\mathrm{c}}$ & 3.82 & $<0.0001$ \\
\hline \multicolumn{5}{|l|}{ Manganese } & 0.97 \\
\hline $\mathrm{CON}$ & 181.0 & 186.2 & 196.2 & 6.84 & \multirow{4}{*}{0.87} \\
\hline INO & 184.9 & 188.4 & 196.1 & 5.72 & \\
\hline ORG & 182.5 & 186.4 & 197.8 & 5.96 & \\
\hline Overall & $182.8^{\mathrm{a}}$ & $187.0^{\mathrm{b}}$ & $196.7^{\mathrm{c}}$ & 3.52 & \\
\hline \multicolumn{5}{|l|}{ Copper } & \multirow[t]{2}{*}{0.97} \\
\hline $\mathrm{CON}$ & 53.8 & 55.4 & 56.4 & 2.04 & \\
\hline INO & 55.0 & 56.0 & 58.3 & 1.70 & \multirow{2}{*}{0.87} \\
\hline ORG & 54.3 & 55.4 & 58.8 & 1.71 & \\
\hline Overall & $54.4^{\mathrm{a}}$ & $55.6^{\mathrm{b}}$ & $58.5^{\mathrm{c}}$ & 1.05 & $<0.0001$ \\
\hline \multicolumn{5}{|l|}{ Cobalt } & 0.97 \\
\hline $\mathrm{CON}$ & 1.9 & 1.9 & 2.1 & 0.07 & \multirow[b]{4}{*}{$<0.0001$} \\
\hline INO & 1.9 & 2.0 & 2.0 & 0.06 & \\
\hline ORG & 1.9 & 1.9 & 2.1 & 0.06 & \\
\hline Overall & $1.9^{\mathrm{a}}$ & $2.0^{\mathrm{b}}$ & $2.1^{\mathrm{c}}$ & 0.04 & \\
\hline \multirow{2}{*}{\multicolumn{6}{|c|}{$\begin{array}{l}\mathrm{a,b,c} \text { Within a row, means without a common superscript differ }(P<0.05) . \\
{ }^{1} \text { Least squares means for average daily intakes of trace minerals from grain in each } \\
\text { treatment group }(\mathrm{n}=3) \text { by period }(\mathrm{n}=3) \text {. }\end{array}$}} \\
\hline & & & & & \\
\hline \multirow{2}{*}{\multicolumn{6}{|c|}{$\begin{array}{l}{ }^{2} \text { Least squares means for average daily intake within a period across all treatment groups } \\
(\mathrm{n}=21) \text {. } \\
{ }^{3} \mathrm{SEM}=\text { standard error of least squares means. }\end{array}$}} \\
\hline & & & & & \\
\hline \multicolumn{6}{|c|}{$\begin{array}{l}{ }^{4} \mathrm{P} \text {-value for treatment, treatment by period interaction, and period, respectively for each } \\
\text { trace mineral. }\end{array}$} \\
\hline
\end{tabular}


Table 11. Average daily intake ${ }^{1}$ of zinc, manganese, copper, and cobalt by period in yearlings consuming different types of hay and being supplemented with no trace minerals $(\mathrm{CON})$, inorganic trace minerals (INO), or organic trace minerals (ORG) $(\mathrm{mg} / \mathrm{hd} / \mathrm{d})$

\begin{tabular}{|c|c|c|c|c|c|}
\hline \multirow[b]{2}{*}{ Trace Mineral } & \multicolumn{4}{|c|}{ Period } & \multirow[b]{2}{*}{ P-value } \\
\hline & 1 & 2 & 3 & $\mathrm{SEM}^{3}$ & \\
\hline Zinc & & & & & 0.99 \\
\hline $\mathrm{CON}$ & 69.1 & 102.9 & 79.6 & 2.80 & \\
\hline INO & 69.4 & 103.1 & 78.5 & 2.57 & 0.61 \\
\hline ORG & 67.3 & 105.1 & 78.2 & 2.85 & \\
\hline Overall $^{2}$ & $68.6^{\mathrm{a}}$ & $103.7^{b}$ & $78.8^{\mathrm{c}}$ & 1.60 & $<0.0001$ \\
\hline Manganese & & & & & 0.97 \\
\hline $\mathrm{CON}$ & 263.9 & 192.5 & 245.3 & 8.29 & \\
\hline INO & 265.1 & 192.9 & 241.8 & 7.95 & 0.63 \\
\hline ORG & 257.1 & 196.6 & 240.9 & 8.72 & \\
\hline Average & $262.1^{\mathrm{a}}$ & $194.0^{\mathrm{b}}$ & $242.7^{\mathrm{c}}$ & 4.82 & $<0.0001$ \\
\hline Copper & & & & & 0.99 \\
\hline $\mathrm{CON}$ & 15.7 & 23.2 & 25.5 & 0.75 & \\
\hline INO & 15.8 & 23.3 & 25.1 & 0.69 & 0.70 \\
\hline ORG & 15.3 & 23.7 & 25.0 & 0.78 & \\
\hline Average & $15.6^{\mathrm{a}}$ & $23.4^{\mathrm{b}}$ & $25.2^{\mathrm{c}}$ & 0.43 & $<0.0001$ \\
\hline \multicolumn{6}{|l|}{ Cobalt } \\
\hline $\mathrm{CON}$ & 0.00 & 0.00 & 0.00 & -- & -- \\
\hline INO & 0.00 & 0.00 & 0.00 & -- & -- \\
\hline ORG & 0.00 & 0.00 & 0.00 & -- & -- \\
\hline Average & 0.00 & 0.00 & 0.00 & -- & -- \\
\hline
\end{tabular}

a,b,c Within a row, means without a common superscript differ $(P<0.01)$.

${ }^{1}$ Least squares means for ADI of trace minerals from hay by treatment groups $(n=3)$ in each period $(\mathrm{n}=3)$.

${ }^{2}$ Average daily intake within a period across all treatment groups $(\mathrm{n}=21)$.

${ }^{3} \mathrm{SEM}=$ standard error of least squares means.

${ }^{4} P$-value for the effect of treatment, treatment $\mathrm{x}$ period, and period on ADI of each trace mineral. 
Table 12. Average daily intake ${ }^{1}$ of zinc, manganese, copper, and cobalt from trace mineral supplements in yearlings receiving no supplementation $(\mathrm{CON})$, inorganic trace minerals (INO), and organic trace minerals (ORG) $(\mathrm{mg} / \mathrm{hd} / \mathrm{d})$

\begin{tabular}{|c|c|c|c|c|c|}
\hline \multirow[b]{2}{*}{ Trace Mineral } & \multicolumn{3}{|c|}{ Period } & \multirow[b]{2}{*}{$\mathrm{SEM}^{3}$} & \multirow[b]{2}{*}{ P-value } \\
\hline & 1 & 2 & 3 & & \\
\hline Zinc & & & & & $<0.0001$ \\
\hline $\mathrm{CON}$ & $0.0^{\mathrm{A}}$ & $0.0^{\mathrm{A}}$ & $0.0^{\mathrm{A}}$ & -- & \\
\hline INO & $333.8^{\mathrm{B}}$ & $347.6^{\mathrm{B}}$ & $359.3^{\mathrm{B}}$ & 10.46 & $<0.0001$ \\
\hline ORG & $357.3^{B}$ & $373.4^{\mathrm{C}}$ & $386.4^{\mathrm{C}}$ & 10.62 & \\
\hline Overall $^{2}$ & $230.4^{\mathrm{a}}$ & $240.3^{\mathrm{b}}$ & $248.6^{c}$ & 5.0 & $<0.0001$ \\
\hline Manganese & & & & & $<0.0001$ \\
\hline $\mathrm{CON}$ & $0.0^{\mathrm{A}}$ & $0.0^{\mathrm{A}}$ & $0.0^{\mathrm{A}}$ & -- & \\
\hline INO & $295.8^{\mathrm{B}}$ & $308.1^{\mathrm{B}}$ & $318.5^{\mathrm{B}}$ & 9.29 & $<0.0001$ \\
\hline ORG & $338.3^{C}$ & $353.4^{\mathrm{C}}$ & $365.7^{\mathrm{C}}$ & 10.05 & \\
\hline Overall & $211.3^{\mathrm{a}}$ & $220.5^{\mathrm{b}}$ & $228.1^{\mathrm{c}}$ & 4.56 & $<0.0001$ \\
\hline Copper & & & & & $<0.0001$ \\
\hline $\mathrm{CON}$ & $0.0^{\mathrm{A}}$ & $0.0^{\mathrm{A}}$ & $0.0^{\mathrm{A}}$ & -- & \\
\hline INO & $136.2^{\mathrm{B}}$ & $141.8^{\mathrm{B}}$ & $146.6^{\mathrm{B}}$ & 4.28 & $<0.0001$ \\
\hline ORG & $125.4^{\mathrm{C}}$ & $131.0^{\mathrm{C}}$ & $135.6^{\mathrm{C}}$ & 3.73 & \\
\hline Overall & $87.2^{\mathrm{a}}$ & $91.0^{\mathrm{b}}$ & $94.1^{\mathrm{c}}$ & 1.89 & $<0.0001$ \\
\hline Cobalt & & & & & $<0.0001$ \\
\hline $\mathrm{CON}$ & $0.0^{\mathrm{A}}$ & $0.0^{\mathrm{A}}$ & $0.0^{\mathrm{A}}$ & -- & \\
\hline INO & $1.9^{\mathrm{B}}$ & $2.1^{\mathrm{B}}$ & $2.1^{\mathrm{B}}$ & 0.06 & $<0.0001$ \\
\hline ORG & $4.0^{\mathrm{C}}$ & $4.2^{\mathrm{C}}$ & $4.3^{\mathrm{C}}$ & 0.12 & \\
\hline Overall & $2.0^{\mathrm{a}}$ & $2.1^{\mathrm{b}}$ & $1.9^{c}$ & 0.04 & $<0.0001$ \\
\hline
\end{tabular}

${ }_{\mathrm{A}, \mathrm{B}, \mathrm{C}}$ Within a column, within the same mineral category, means without a common superscript differ $(P<0.05)$.

${ }^{\mathrm{a}, \mathrm{b}, \mathrm{c}}$ Within a row, means without a common superscript differ $(P<0.05)$.

${ }^{1}$ Least squares means for ADI of trace minerals from supplements by treatment groups $(n=3)$ in each period $(n=3)$.

${ }^{2}$ Least squares means for ADI of trace minerals from supplements across all treatment groups by period.

${ }^{3} \mathrm{SEM}=$ standard error of least squares means.

${ }^{4} P$-value for effect of treatment, treatment x period, and period on ADI of trace minerals from supplement.

There was a treatment effect $(P<0.0001)$ and a period effect $(P<0.0001)$ for ADI of the individual trace minerals from the supplements (Table 12). All 3 treatment groups were different, with the CON receiving no supplement, therefore being lower 
than the INO and ORG. The ORG group consumed more supplemental Zn, Mn, and Co. In contrast, the INO had a higher intake of $\mathrm{Cu}$ from the trace mineral supplement. In reference to the period effect observed, those yearlings being supplemented with trace minerals had a higher ADI of all individual minerals with each consecutive period. Thus, the lowest ADI from supplementation occurred in Period 1, with the highest in Period 3.

Total trace mineral intakes were determined by combining the concentrations consumed in the grain, hay, and supplement (Table 13, 14, and 15). For Zn, there was a treatment effect $(P<0.0001)$, with the CON consuming less than INO or ORG. There was no difference in total $\mathrm{Zn}$ intake between the INO and ORG $(P=0.29)$. There was a period effect $(P<0.0001)$, with Periods 1,2 , and 3 all being different. Period 1 had the lowest total Zn intake, followed by Period 2, and Period 3 had the highest intake. Total Mn intake was also different as an effect of treatment $(P<0.0001)$ and period $(P<$ 0.0001). Once again, CON was lower than both INO and ORG, but the 2 supplemented groups were not different $(P=0.14)$. Periods 1 and 3 were not different, but were both greater than Period $2(P<0.0001)$. The treatment effect $(P<0.0001)$ for total $\mathrm{Cu}$ intake reflects INO and ORG not being different $(P=0.14)$, but both being greater than $\mathrm{CON}$ $(P<0.0001)$. There also was a period effect $(P<0.0001)$ with each period having a lower $\mathrm{Cu}$ intake than the subsequent period. Finally, Co intake had a treatment and period effect $(P<0.0001)$, with all treatments and periods being significantly different. The CON had a lower total $\mathrm{Cu}$ intake than both INO and ORG, while ORG consumed 
more than INO. The total Co intake also increased with each period, resulting in the lowest values in Period 1 and the highest in Period 3.

Table 13. Average total ${ }^{1}$ daily intake of the trace minerals zinc, manganese, copper, and cobalt in yearling horses supplemented with no trace minerals $(\mathrm{CON})$, inorganic trace minerals (INO), or organic trace minerals (ORG) by period (mg/hd/d) (100\% DM basis)

\begin{tabular}{|c|c|c|c|c|c|c|c|c|c|c|c|c|}
\hline & \multicolumn{12}{|c|}{ Treatment } \\
\hline & \multicolumn{4}{|c|}{$\mathrm{CON}$} & \multicolumn{4}{|c|}{ INO } & \multicolumn{4}{|c|}{$\mathrm{ORG}$} \\
\hline & \multicolumn{4}{|c|}{ Trace Mineral } & \multicolumn{4}{|c|}{ Trace Mineral } & \multicolumn{4}{|c|}{ Trace Mineral } \\
\hline Period & $\mathrm{Zn}$ & $\mathrm{Mn}$ & $\mathrm{Cu}$ & $\mathrm{Co}$ & $\mathrm{Zn}$ & $\mathrm{Mn}$ & $\mathrm{Cu}$ & $\mathrm{Co}$ & $\mathrm{Zn}$ & $\mathrm{Mn}$ & $\mathrm{Cu}$ & $\mathrm{Co}$ \\
\hline 1 & 266 & 445 & 70 & 2 & 604 & 746 & 207 & 4 & 623 & 778 & 195 & 6 \\
\hline 2 & 305 & 379 & 79 & 2 & 655 & 689 & 221 & 4 & 681 & 736 & 210 & 6 \\
\hline 3 & 293 & 442 & 84 & 2 & 651 & 756 & 230 & 4 & 679 & 804 & 219 & 6 \\
\hline Average & 288 & 422 & 77 & 2 & 637 & 730 & 219 & 4 & 661 & 773 & 208 & 6 \\
\hline
\end{tabular}

${ }^{1}$ Least squares means for total ADI of individual trace minerals by treatment and period.

Table 14. Average daily intake ${ }^{1}$ of zinc, manganese, copper, and cobalt in yearlings supplemented with no trace mineral $(\mathrm{CON})$, inorganic trace mineral (INO), or organic trace mineral (ORG) across all periods (100\% DM basis)

\begin{tabular}{lcccc}
\hline \hline & \multicolumn{3}{c}{ Trace Minerals $(\mathrm{mg} / \mathrm{hd} / \mathrm{d})$} & \\
\cline { 2 - 4 } Treatment & Zinc & Manganese & Copper & Cobalt \\
\hline CON & $288^{\mathrm{a}}$ & $422^{\mathrm{a}}$ & $77^{\mathrm{a}}$ & $2^{\mathrm{a}}$ \\
INO & $637^{\mathrm{b}}$ & $730^{\mathrm{b}}$ & $219^{\mathrm{b}}$ & $4^{\mathrm{b}}$ \\
ORG & $661^{\mathrm{b}}$ & $773^{\mathrm{b}}$ & $208^{\mathrm{b}}$ & $6^{\mathrm{c}}$ \\
\hline
\end{tabular}

${ }^{\mathrm{a}, \mathrm{b}, \mathrm{c}}$ Within a column, means without a common superscript differ $(\mathrm{P}<0.0001)$.

${ }^{1}$ Least squares means of average daily trace mineral intake across all periods $(n=3)$.

Table 15. Average daily intake of zinc, manganese, copper, and cobalt across all treatments by period (100\% DM basis)

\begin{tabular}{|c|c|c|c|c|c|}
\hline \multirow[b]{2}{*}{ Trace Mineral } & \multicolumn{3}{|c|}{ Period } & \multirow[b]{2}{*}{ SEM } & \multirow[b]{2}{*}{ P-value } \\
\hline & 1 & 2 & 3 & & \\
\hline$\overline{Z i n c}$ & $497.4^{\mathrm{a}}$ & $547.0^{b}$ & $540.8^{c}$ & 9.23 & $<0.0001$ \\
\hline Manganese & $656.2^{\mathrm{a}}$ & $601.5^{\mathrm{b}}$ & $667.4^{\mathrm{a}}$ & 11.46 & $<0.0001$ \\
\hline Copper & $157.2^{\mathrm{a}}$ & $170.0^{\mathrm{c}}$ & $177.8^{\mathrm{c}}$ & 3.02 & $<0.0001$ \\
\hline Cobalt & $3.9^{\mathrm{a}}$ & $4.0^{\mathrm{b}}$ & $4.2^{c}$ & 0.07 & $<0.0001$ \\
\hline
\end{tabular}

${ }^{\mathrm{a}, \mathrm{b}, \mathrm{c}}$ Within a row, means without a common superscript differ $(\mathrm{P}<0.05)$. 


\section{Growth Parameters}

Body Condition Score. Mean BCS ranged from 5.1 to 6.1 throughout the trial. There was not a treatment effect on BCS $(P=0.48)$ or a treatment by period interaction $(P=0.38)$. However, there was a period effect $(P<0.0001)$, such that all periods were different than all other periods (Table 16). The mean BCS for Period 1 were significantly lower than baseline $(P=0.01)$. By the conclusion of Period 2, BCS had significantly increased $(P<0.0001)$ and continued to do so with each subsequent period. So, the lowest BCS of the trial were recorded in Period 1, with the highest being determined in Period 3.

Body Weight. There was no difference in initial body weight among the treatment groups $(P=0.75)$, which was expected as yearlings were blocked by body weight in addition to EGUS score (Table 16). There was no treatment effect on body weight $(P=0.87)$, or a treatment by period interaction $(P=0.88)$. There was a period effect $(P<0.0001)$ with all periods being different from one another. All treatment groups gained weight with each period (Table 16). Body weights also were analyzed by day in order to detect the changes throughout the entire trial (Figure 5). All time-points (days) were significantly heavier than the previous BW, as yearlings were continuously gaining weight, with a few exceptions. As points of reference on the graph below and for the discussion on the behavior of BW throughout the trial, $\mathrm{d} 28,63$, and 98 represent the conclusion of Periods 1, 2, and 3, respectively. Day 0 and 7, were not different. Additionally, there was no difference in BW between $\mathrm{d} 21,28$, and 35 . There also was not a difference in BW at $\mathrm{d} 49$ and $\mathrm{d} 70$. The BW values recorded on $\mathrm{d} 56,63$, and 77 
also were not different. Finally, d 70 was the only time-point in which BW was significantly lower than the previous measurement, however, BW had significantly increased again by $\mathrm{d} 77$.

Table 16. Growth parameters, ${ }^{1}$ including body condition score (BCS), body weight $(\mathrm{BW})$, total gain, and average daily gain (ADG) of yearling horses supplemented with no trace mineral $(\mathrm{CON})$, inorganic trace mineral (INO), or organic trace mineral (ORG)

\begin{tabular}{|c|c|c|c|c|c|c|}
\hline \multirow[b]{2}{*}{ Item } & \multicolumn{4}{|c|}{ Period } & \multirow[b]{2}{*}{$\mathrm{SEM}^{2}$} & \multirow[b]{2}{*}{$P$-value ${ }^{3}$} \\
\hline & Baseline & 1 & 2 & 3 & & \\
\hline$\overline{\mathrm{BCS}}$ & & & & & & 0.48 \\
\hline $\mathrm{CON}$ & 5.2 & 4.7 & 5.6 & 5.9 & 0.24 & \\
\hline INO & 5.5 & 5.3 & 5.9 & 6.1 & 0.25 & 0.38 \\
\hline ORG & 5.4 & 5.3 & 5.8 & 6.1 & 0.22 & \\
\hline Overall $^{4}$ & $5.4^{\mathrm{a}}$ & $5.1^{\mathrm{b}}$ & $5.8^{\mathrm{c}}$ & $6.0^{\mathrm{d}}$ & 0.14 & $<0.0001$ \\
\hline $\mathrm{BW}, \mathrm{kg}$ & & & & & & 0.87 \\
\hline $\mathrm{CON}$ & 361.6 & 376.1 & 396.1 & 416.4 & 13.93 & \\
\hline INO & 369.4 & 381.4 & 401.8 & 418.1 & 12.23 & 0.88 \\
\hline ORG & 374.0 & 385.5 & 405.3 & 422.4 & 12.01 & \\
\hline Overall & $368.3^{\mathrm{a}}$ & $381.0^{\mathrm{b}}$ & $401.1^{\mathrm{c}}$ & $419.0^{\mathrm{d}}$ & 7.37 & $<0.0001$ \\
\hline Total Gain, kg & & & & & & 0.83 \\
\hline $\mathrm{CON}$ & -- & 14.4 & 21.5 & 24.0 & 2.16 & \\
\hline INO & -- & 12.1 & 20.6 & 25.7 & 1.96 & 0.85 \\
\hline ORG & -- & 11.5 & 19.5 & 25.4 & 2.39 & \\
\hline Overall & -- & $12.7^{\mathrm{a}}$ & $20.5^{b}$ & $25.0^{c}$ & 1.26 & $<0.0001$ \\
\hline $\mathrm{ADG}, \mathrm{kg} / \mathrm{d}$ & & & & & & 0.81 \\
\hline $\mathrm{CON}$ & -- & 0.5 & 0.8 & 0.8 & 0.08 & \\
\hline INO & -- & 0.4 & 0.7 & 0.9 & 0.07 & 0.85 \\
\hline ORG & -- & 0.4 & 0.7 & 0.9 & 0.08 & \\
\hline Overall & -- & $0.4^{\mathrm{a}}$ & $0.7^{\mathrm{b}}$ & $0.9^{\mathrm{c}}$ & 0.04 & $<0.0001$ \\
\hline
\end{tabular}

${ }_{\mathrm{a}, \mathrm{b}, \mathrm{c}, \mathrm{d}}$ Within a row, means without a common superscript differ $(P<0.05)$.

${ }^{1}$ Least squares means for individual treatment groups $(n=3)$ in each period $(n=4)$.

${ }^{2} \mathrm{SEM}=$ standard error of least square means.

${ }^{3} P$-Value for treatment, treatment by period interaction, and period, respectively for each growth parameter.

${ }^{4}$ Overall $=$ Least squares means across all treatment groups $(\mathrm{n}=21)$ within each period $(n=4)$. 


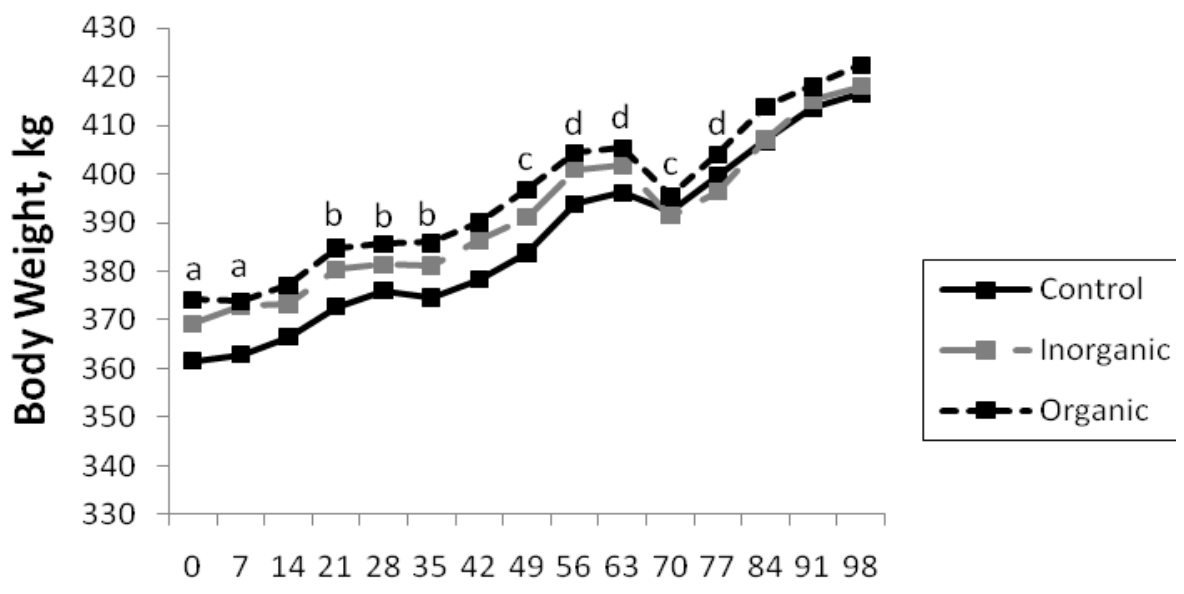

Day

Figure 5. Mean body weights by day for yearling horses consuming no trace mineral (Control), inorganic trace mineral (Inorganic), or organic trace mineral (Organic).

a,b,c,d Days sharing a common letter are not different $(\mathrm{P} \geq 0.05)$.

Total Gain. There was no treatment effect on total weight gain $(P=0.83)$ in any period, resulting in no treatment by period interaction $(P=0.85)$. However, there was a period effect $(\mathrm{P}<0.0001)$ (Table 16). The yearlings gained weight in every period, with each period being significantly higher than during the previous period. The lowest mean weight gain occurred in Period 1 at $12.67 \mathrm{~kg}$, while Period 3 was the highest at $25.0 \mathrm{~kg}$, with Period 2 having an intermediate total gain of $20.5 \mathrm{~kg}$.

Average Daily Gain. There was no effect of treatment on average daily gain $(\mathrm{ADG})(P=0.81)$ in any period, which resulted in no period by treatment interaction $(P$ $=0.85$ ) (Table 6). However, there was a period effect, with all 3 periods being different, as ADG increased during each period $(P<0.0001)$. The greatest difference in ADG occurred between Periods 1 and 2, with a mean ADG of $0.44 \mathrm{~kg} / \mathrm{d}$ and $0.75 \mathrm{~kg} / \mathrm{d}$, respectively. Moreover, the highest ADG was in Period 3 at $0.89 \mathrm{~kg} / \mathrm{d}$. 


\section{CHAPTER V}

\section{DISCUSSION}

\section{Ulcer Score}

The prevalence of ulcer scores was high at baseline endoscopies (76\%), especially when compared to a previous EGUS study conducted at Texas A\&M on the 2005 yearling horses, which were managed similar to the horses in the current study (Lybbert, 2007). In the previous study, 33\% of yearlings had an ulcer score of 2 or greater compared to the $76 \%$ in the current study. Research has reported that horses maintained on pasture are in a less stressful environment and have lower ulcer scores than horses that are confined, as well as pasture turn-out being a remedy for horses diagnosed with EGUS (Murray and Eichorn, 1996; Vatistas et al., 1999b; Buchanan and Andrews, 2003). However, our data more closely resembles more recent studies by le Jeune et al. (2008) and Bell et al. (2007b) in which 71\% and 100\%, respectively of horses at pasture had evidence of squamous ulceration. Additionally, the study reported by Lybbert (2007) included a 21-d washout period and horses had a higher incidence of ulcers after $21 \mathrm{~d}$ on pasture.

It has been well documented that horses in training are more susceptible to gastric ulcer formation (Murray et al., 1996; Vatistas et al., 1999a, b; Lorenzo-Figueras, 2003; White et al., 2007). At baseline endoscopies, yearlings were participating in an undergraduate halter breaking and training class, but the activities performed would not be considered as demanding as those studies cited above. So, the magnitude of training 
which might influence baseline ulcer scores is questionable. Furthermore, yearlings were consuming a pelleted concentrate when baseline endoscopies were conducted. It has been documented in pigs that feeding a pelleted concentrate results in more severe ulceration than feeding a textured concentrate (Amory et al., 2006). The yearlings were transitioned from the pelleted concentrate to a textured grain between baseline endoscopies and the initiation of Period 1. Lybbert (2007) also investigated gastric ulcers in yearling horses and fed a similar pelleted concentrate, but only $33 \%$ of yearlings had ulcers at baseline. However, in that study the horses continued to consume a pelleted ration throughout the study and never transitioned to a different concentrate type. Conceivably, concentrate type might possibly play a role in gastric ulcer formation.

Stress associated with the competition for food could have contributed to higher ulcer scores at baseline. While horses were maintained on pasture prior to Period 1, they were group-fed the pelleted concentrate. It is possible that under this circumstance, yearlings were required to compete for grain which imposed a stressful situation during meals. However, during the trial, horses consumed their meals in individual stalls which negated the competition for feed.

Another factor to consider in reference to the high prevalence of gastric ulcers in the yearlings at baseline is the dynamic nature of EGUS (Murray and Eichorn, 1996; Bell et al., 2007a). Baseline endoscopies were conducted 3 mo prior to the commencement of Period 1. Given the dynamic nature of ulcers, this is a possible 
confounding variable in the change in ulcer score between baseline and the conclusion of Period 1.

There were only 3 horses with glandular ulcers detected throughout the entire trial. These findings are in agreement with other studies in which glandular ulcers were less common than non-glandular (Murray et al., 1989; McClure et al., 1999; Dionne et al., 2003). A noteworthy observation also is that the glandular ulcers were detected in a horse on the ORG treatment and INO treatment at the conclusion of Period 1, with a CON horse having a glandular ulcer in Period 3. All 3 of these horses had an ulcer score of 0 for the non-glandular region and a glandular ulcer score of 2. Interestingly enough, CB hay was fed in Periods 1 and 3, with ALF being consumed in Period 2, when no glandular ulcers were recorded. Moreover, Furr et al. (1992) reported a higher incidence of glandular ulcers in foals stressed by disease, suggesting that stress plays a role in the site of ulcer formation. The filly from the INO treatment group with a glandular ulcer at the conclusion of Period 1 was injured during the $6 \mathrm{~h}$ transportation. During the last $2 \mathrm{~h}$ of hauling, she fell down in the trailer and required encouragement by handlers for her to stand and exit the trailer, and was treated for abrasions, lacerations, and swelling in her hocks, fetlocks, and carpi. Therefore, it is possible that the stress of this situation contributed to the development of her glandular ulcer. Additionally, the second horse with a glandular ulcer in Period 1 from the ORG treatment group was turned loose during transportation in the same group with INO filly and was treated for numerous abrasions, as well as a swollen hock following the transport. An INO horse received a 
substantial laceration on her right front fetlock during transportation at the end of Period 2. She had a non-glandular ulcer score of 2 for this period.

There was no treatment effect $(P=0.24)$ of trace mineral supplementation on gastric ulcers in any period. It is possible that the anti-ulcerogenic effect of amino acid complexed trace minerals is tissue or species specific. Previous preliminary data showed a reduction in the intestinal lesions of broilers (Zinpro, 2004). However, the same effect was not observed in the gastric ulcers of horses in this study. Trace minerals are absorbed in the small intestine which might allow them to be utilized at a higher rate at this site (McDonald et al., 2002). An additional explanation is the difference in cell type and the environments to which each particular cell type is exposed. Stratified squamous epithelia in the non-glandular region of the stomach have minimal protection, including interepithelial tight junctions and limited exposure to acid (Andrews et al., 2005). On the other hand, columnar epithelial found in the small intestine are protected by a mucosal layer, which can serve as a defense mechanism against acidity. Additionally, upon damage, the villus of the small intestine is retracted from the lumen for restitution (Dunlop and Malbert, 2004). The retraction of the villus decreases the surface area to repair and could be more conducive to repair by protecting the injured cells from the luminal contents of the small intestine (Moore et al., 1989). Since the non-glandular stomach is covered by several more planar layers of stratified squamous epithelium, it is possible that injured cells continue to be exposed to a destructive environment, which could impede cellular repair. Epithelial restitution is a rapid process for villi, as cells continually germinate and migrate from the basal membrane toward the villus tip. 
Under normal conditions, epithelial cells in this portion of the gastrointestinal tract also have a short life span, being sloughed into the intestinal lumen and replaced within days. Since the turn-over rate is high under normal physiologic conditions, it is possible that restitution as a result of injury would also occur rapidly (Dieckgraefe et al., 1996; Dunlop and Malbert, 2004). Conversely, in stratified squamous epithelial repair, replication is necessary from the stratum germinativum. These cells must also mature and migrate to the stratum corneum in order to complete restitution and re-establish the stratified squamous epithelial lining (Argenzio, 1999; Eurell et al., 2006; Orlando, 2006).

It is also possible that different results would have been observed if horses were actually deficient in trace minerals before the trial or were exposed to a more stressful situation than the $6 \mathrm{~h}$ transport. However, in a partner study, blood samples were collected on these horses and an increase in cortisol concentration during the $6 \mathrm{~h}$ of transport was observed indicating that this event was stressful enough to induce an endocrine response (Garey, 2009). The number of horses who refused hay $5 \mathrm{~d}$ prior to transportation and in the $5 \mathrm{~d}$ following transportation was determined, along with the average hay refusal collected. Although this data was not statistically analyzed, it does appear that after hauling, the yearlings had a decreased forage intake, especially in Periods 1 and 2, as typically there was a slight increase in average refusal amount collected and more horses refusing hay (Appendix 6). Differences in intestinal lesions were not observed in the Zinpro (2004) study until d 42. 
There was a period effect $(P<0.01)$, with baseline mean ulcer scores being significantly higher than in Periods 1, 2, or 3, as discussed above. The mean ulcer score observed in Period 2 was 1.0 , which tended $(P=0.06)$ to be lower than the observed mean ulcer score of 1.5 in Periods 1 and 3. During Period 2, ALF hay was consumed by the yearlings. Previous research has reported a lower ulcer score in horses consuming ALF compared to those consuming grass hay (Nadeau et al., 2000; Lybbert, 2007). Additionally, the study reported by Lybbert (2007) utilized yearling horses and compared ALF with CB. Therefore, it is possible that hay type contributed to the downward trend in ulcer score from Period 1 to 2 and upward trend in ulcer score from Period 2 to 3, when horses were transitioned from ALF back to CB. Although Period 3 encompassed several changes beyond that of hay type, including a change in environment, being individually stalled, and a change in exercise, mean ulcer score did not differ from Period $1(P=1.0)$, as both were 1.5. Moreover, the change in mean ulcer score between those periods were -0.48 from Period 1 to 2 and +0.48 from Period 2 to 3 . In a companion project, blood samples were drawn prior to hauling (basal), at 2-h intervals during hauling, and post-hauling. Results of cortisol concentrations revealed that there was no difference in basal levels prior to hauling in Periods 1 or 2 , but basal concentrations were significantly higher in all horses in Period 3 (Garey, 2009). This occurred when horses were housed in individual stalls and being used in a breaking and training class. However, an increase in mean ulcer scores for this period was not associated with the higher basal cortisol levels, as mean ulcer score for Periods 1 and 3 were not different. Furthermore, stall confinement and training has been suggested to be 
associated with higher ulcer scores than pasture turn-out (Murray and Eichorn, 1996; Andrews et al., 2002; McClure et al., 2005a). However, data from the present study more closely resembles Bell et al. (2007b), which reported no difference in race horses in training that were stalled versus turn-out. Additionally, the yearlings were muzzled during the $18 \mathrm{~h}$ fast in Period 3, but not in the previous 2 periods. This also could have been a contributing factor to an increase in ulcer formation. Although ulcer scores did increase in Period 3, there also were several other confounding factors in that period, and mean ulcers scores did not exceed baseline when the yearlings were maintained at pasture.

Coprophagy was observed to be a frequent behavior in the majority of the yearlings. Although no refereed articles could be located to discuss the possible effects of coprophagy on ulcer formation, it is conceivable that fecal material may have a protective effect on the squamous epithelium. During a previous study in which ulcers were induced by using the model of intermittent feed deprivation (Murray, 1994), researchers experienced difficultly in causing ulcers. Once horses were muzzled to prevent coprophagy, squamous gastric ulceration was consistently induced (Cohen, 2008).

Although numerous factors including diet, environment, exercise, and housing were altered between baseline endoscopies and among the periods, most notably Periods 2 and 3, the severity of ulcer scores never exceeded values determined at baseline. There were 9 horses that received an ulcer score of 3 at baseline endoscopy. However, no horse received an ulcer score this high (above a 2) throughout all 3 periods of the 
trial. Thus, baseline ulcers were more prevalent and severe than during any of the 3 periods encompassed by the trial. Although horses were given at least $28 \mathrm{~d}$ to acclimate to the new situations introduced among the periods, the lower mean ulcer scores throughout the trial in comparison to baseline values calls into question the detrimental effects of some putative risk factors.

\section{Grain, Hay, and Supplement Intake}

Grain intake increased $(P<0.0001)$ with each period as horses were fed per BW. There was also a period effect for hay intake $(P<0.0001)$ with Period 2 having a significantly higher intake than Periods 1 or 3. In Period 2 ALF hay was consumed, with CB fed in Periods 1 and 3. Hay type could have played a role in intake, as previous research has documented yearling horses to have higher DMI and prefer ALF over grass hay (LaCasha et al., 1999). Higher intakes of hay in Period 2, as well as higher overall intakes of CP and DE (Table 17) could have also contributed to the increase in BW, BCS, ADG, and total gain discussed below. Subjectively, horses consumed ALF more readily than grass hay. Total hay refusals collected for Period 1, 2, and 3 were $132 \mathrm{~kg}$, $38 \mathrm{~kg}$, and $270 \mathrm{~kg}$, respectively. Furthermore, mean hay refusal per head for Periods 1 , 2, and 3 was $5.2 \mathrm{~kg}, 1.7 \mathrm{~kg}$, and $13.0 \mathrm{~kg}$, respectively. Supplement intakes did have a treatment effect $(P<0.0001)$, as INO and ORG consumed more than CON. This is obvious and expected, as $\mathrm{CON}$ received no trace mineral supplementation. Trace mineral supplements were fed on a BW basis, so the increase intake across periods $(P<$ $0.0001)$ is attributed to increased BW throughout the trial. 
Total DMI had a period effect $(P<0.0001)$ but not a treatment effect $(P=0.99)$.

Periods 2 and 3 were significantly higher than Period 1. Once again, this was attributed to the fact horses were fed per BW and continued to gain weight, which increased intake. The significantly higher hay intake in Period 2 compensated for the increased feeding level because of BW in Period 3, resulting in Periods 2 and 3 not being different in total DMI. In reference to the NRC (2007) recommendations for nutrient intake, yearlings in the current study received $>120 \%$ of the requirement for DE and CP (Table 17).

Table 17. Mean daily nutrient intake of yearling horses by period across all treatment groups in reference to the NRC (2007)

\begin{tabular}{lcrrr}
\hline & & \multicolumn{3}{c}{ Period } \\
\cline { 3 - 5 } Nutrient & NRC Requirement & \multicolumn{1}{c}{1} & \multicolumn{1}{c}{2} & \multicolumn{1}{c}{3} \\
\hline CP, g & 853.0 & 939.6 & 1342.7 & 1065.3 \\
DE, Mcal & 22.1 & 25.7 & 28.2 & 27.3 \\
Ca, g & 37.0 & 56.8 & 107.7 & 60.3 \\
P,g & 20.6 & 24.0 & 28.2 & 26.2 \\
Mg, g & 11.6 & 13.6 & 22.9 & 15.1 \\
$\mathrm{~K}, \mathrm{~g}$ & 25.7 & 77.6 & 124.7 & 84.7 \\
$\mathrm{Na}, \mathrm{g}$ & 14.0 & 13.5 & 15.7 & 16.1 \\
\hline
\end{tabular}

\section{Trace Mineral Intake}

The only difference in trace mineral intake from grain was a result of adjusted feeding levels. There was a period effect on ADI of $\mathrm{Zn}, \mathrm{Mn}, \mathrm{Co}$, and $\mathrm{Cu}$, however, this difference is a combination of BW as well as the fact that different hay types were fed in each period. All 3 periods were different, with $\mathrm{Zn}$ intake from the hay being highest in Period 2, followed by Period 3, with the lowest intake in Period 1. These differences are 
a result of the concentration of $\mathrm{Zn}$ in each hay source with ALF having the highest and the $\mathrm{CB}$ fed in Period 3 being higher than the source fed in Period 1. Examination of the hay analysis reveals that CB hay is higher in Mn than ALF. Therefore, intakes of Mn from hay were highest in the Period $1 \mathrm{CB}$, followed by the Period $3 \mathrm{CB}$, and ALF being the lowest. The intakes of $\mathrm{Cu}$ from hay were also a result of differing concentrations with all 3 periods being different. Period $3 \mathrm{CB}$ had the highest concentration of $\mathrm{Cu}$, with Period $1 \mathrm{CB}$ having the lowest, and ALF being intermediate. The laboratory that analyzed the hays is not capable of Co analysis. Cobalt contributed from the hay was calculated to be 0 , as this trace mineral is negligible in forage (NRC, 2007).

The differences in trace mineral intake from the supplement were a result of changes in body weight and different levels of trace minerals in both the supplement mixtures.

There was a treatment and period effect on total trace mineral intakes of $\mathrm{Zn}, \mathrm{Mn}$, $\mathrm{Cu}$, and $\mathrm{Co}$. This effect was caused by a combination of having a group that was not supplemented, changes in BW, and differences in trace mineral concentrations in the hay sources used. Table 18 shows average daily intake of each trace mineral across all periods by treatment group. The $\mathrm{CON}$ horses were deficient in $\mathrm{Zn}$ and $\mathrm{Cu}$. Values also express adequate separation between this group and the 2 supplemented groups (NRC, 2007) (Table 18). Although the INO and ORG did not have equal intakes of each trace mineral, they were similar ranging from 164 to $227 \%$ above NRC requirements for $\mathrm{Zn}$, $\mathrm{Mn}$, and $\mathrm{Cu}$. For $\mathrm{Co}$, the $\mathrm{CON}$, INO, and ORG exceeded the NRC recommendation by 4, 8, and 12 times, respectively. The INO group received approximately $46 \mathrm{ppm}, 38$ 
ppm, $19 \mathrm{ppm}$, and $0.23 \mathrm{ppm}$ above the $\mathrm{CON}$ of $\mathrm{Zn}, \mathrm{Mn}, \mathrm{Cu}$, and $\mathrm{Co}$, respectively. The ORG consumed approximately 50 ppm, 44 ppm, 18 ppm, and 0.5 ppm of $\mathrm{Zn}, \mathrm{Mn}, \mathrm{Cu}$, and Co, respectively above the average intake of $\mathrm{CON}$ horses. The trace mineral intakes of the horses in the current study are comparable being approximately $100 \mathrm{mg} / \mathrm{hd} / \mathrm{d}$ higher than in a previous report (Ott and Johnson, 2001). However, when compared to trace mineral balance and retention study on organic and inorganic trace minerals, intakes are much lower, with the exception of Co (Naile et al., 2005). Horses in that study also were fed on a BW basis to an expected ending BW.

Table 18. Average daily intake of trace minerals across all 3 periods by treatment group in reference to the NRC (2007)

\begin{tabular}{lcccc}
\hline \hline & \multicolumn{3}{c}{ Trace Minerals $(\mathrm{mg} / \mathrm{hd} / \mathrm{d})$} & \\
\cline { 2 - 4 } Treatment & Zinc & Manganese & Copper & Cobalt \\
\hline NRC Rec. & 387.5 & 387.5 & 96.4 & 0.5 \\
CON & 288 & 442 & 77 & 2 \\
INO & 637 & 731 & 219 & 4 \\
ORG & 661 & 773 & 208 & 6 \\
\hline
\end{tabular}

\section{Growth Parameters}

Body Condition Score. Mean BCS decreased from baseline to the conclusion of Period 1 and significantly increased in each subsequent period, such that all periods were different from one another. Although BCS decreased in Period 1, horses continued to increase in BW. Since yearlings have an additional nutritional requirement for growth, it is possible that the concentration of nutrients, especially in the hay, were adequate to sustain tissue growth as they continued to increase in BW, but not sufficient for adipose 
deposition to increase BCS. From the analysis, the ALF hay used in this trial was higher in $\mathrm{CP}, \mathrm{DE}$, and TDN than the $\mathrm{CB}$. These factors could have contributed to the increase in body condition score over Period 2, with the CB having a lower nutrient-to-calorie ratio than the alfalfa. As visible in Table 17, yearlings consumed more of all the nutrients listed, except for $\mathrm{Na}$, in Period 2. The highest mean BCS was recorded in Period 3. Although horses were consuming CB, as in Period 1, they were confined to a stall, for approximately $23 \mathrm{~h}$ per day. For the previous 2 periods, they had free exercise throughout the day in dry-lots in addition to forced exercise. It is possible that the reduction of exercise resulted in an increase in BCS, as less energy was expended. Furthermore, horses were fed on a per BW basis, not to maintain BCS. So, as BW increased, so did feed offered and DMI, which could have contributed to an increase in body condition.

Body Weight. There was no treatment effect on initial BW $(P=0.75)$, which was expected, as horses were blocked by initial BW. Throughout the trial, there was also no effect of treatment on BW $(P=0.87)$, so trace mineral supplementation did not affect BW gain, since the CON were not different from the 2 supplemented groups. There was a period effect $(P<0.0001)$ with each period having a significantly higher BW than the previous period. The yearlings were in a growth stage and were fed on a per BW basis, not to maintain BW, so an increase in weight was expected. The yearlings in this study were approximately 15 mo of age when the trial was initiated, but were 18 mo of age at the conclusion of Period 3. According to the NRC (2007), suggested BWs are $321 \mathrm{~kg}$ at 12 mo and $387 \mathrm{~kg}$ at $18 \mathrm{mo}$. These yearlings were between suggested weights for 
baseline and Period 1 with BW of $368 \mathrm{~kg}$ and $381 \mathrm{~kg}$, respectively. However, they exceed the NRC suggested weight for the last 2 periods, as they weighed 401 and 419 kgs, respectively. Weights were similar to a previous EGUS study on quarter horse yearlings (Lybbert, 2007). Body weights also were analyzed by d, since measurements were taken every $7 \mathrm{~d}$ in order to visualize the behavior of BW throughout the trial. All $\mathrm{d}$ were significantly heavier from the previous weight with a few exceptions (Figure 5). Horses did not gain weight during the first $7 \mathrm{~d}$ of the trial. Horses were transported $5 \mathrm{~d}$ prior to the end of each period, so hauling would fall between $\mathrm{d} 21$ and 28 for Period 1, d 56 and 63 for Period 2, and d 91 and 98 for Period 3. It has been reported that horses transported for as little as $6 \mathrm{~h}$ do incur some weight loss (Stull et al., 1999). Their BW also remained the same from d 21 to $\mathrm{d} 35$, so they gained no weight from before hauling through the endoscopies and acclimation to ALF. There was a significant increase in BW $7 \mathrm{~d}$ into Period 2. The BW before horses were hauled and after were also the same for Period 2, as d 56 and 63 were not different. Additionally, d 70 represents d 0 for Period 3. Horses had been transported from the Texas A\&M University Horse Center to Freeman Equestrian Center after endoscopic examinations were completed on d 63. Furthermore, these yearlings were naïve to any environment beyond the Horse Center, as all horses were foaled and raised at this location. They had been at the Freeman Arena facility for approximately $6 \mathrm{~d}$ when the Period $3 \mathrm{~d} 0 \mathrm{BW}$ was taken. The yearlings had a significant weight loss to a mean BW similar to $21 \mathrm{~d}$ prior. However, BW significantly increased by $\mathrm{d} 77$ to a BW that was not different than that observed before they changed environments from the Horse Center to Freeman Arena. According to the NRC (2007), 
yearling horses should be fed $2.5 \% \mathrm{BW}$. Even though yearlings in this study were only fed $2.25 \%$ BW, they were still ultimately heavier than the NRC BW for horses of their age and activity level. So, it is possible for yearlings to maintain adequate growth while being fed slightly below the NRC recommendations.

Total Gain and ADG. Total gains significantly increased with each period $(P<$ 0.0001), with the largest difference being between Periods 1 and 2 . It is possible that the DE of the ALF contributed to the increase in gain in Period 2, along with the increase in intake. In Period 3, horses were offered a higher level of concentrate and hay, coupled with a reduction in exercise, which could have contributed this period having the highest total gain of the trial. The ADG had a similar response as total gain and can be explained by the same mechanisms. Additionally, the NRC (2007) ADG recommendation for the age and exercise level of horses in our study is $0.29 \mathrm{~kg} / \mathrm{d}$. However, yearlings in the current study far exceeded this ADG with Periods 1,2 , and 3 being $0.44 \mathrm{~kg} / \mathrm{d}, 0.75 \mathrm{~kg} / \mathrm{d}$, and $0.89 \mathrm{~kg} / \mathrm{d}$, respectively. These ADGs range between 1.5 and 3 times the recommended ADG. 


\section{CHAPTER VI}

\section{SUMMARY AND CONCLUSIONS}

Gastric ulcers are highly prevalent in horses. Research on the condition continues to be diverse, as investigations have evaluated risk factors, in vivo and in vitro mechanisms of injury, incidence among breeds and disciplines, and treatment options. The wider availability of endoscopic equipment for the diagnosis of EGUS may be one explanation for increased recognition of gastric ulcers. However, the specific pathogenesis of ulcer formation has yet to be elucidated. Management of the condition has been based largely on extrapolating information from other species and utilizing acid suppressant products that are effective but expensive. Therefore, investigation into possible dietary or management alternatives are needed to identify more practical and economical strategies for treatment and prevention. The objective of this study was to evaluate the effect of trace mineral supplementation on gastric ulcer appearance and severity, as well as the influence of hay type.

Under the conditions of this study, there was no trace mineral effect on gastric ulcer formation. Although horses were maintained in an environment that could be considered low stress, baseline ulcer scores were significantly higher than in any of the 3 periods encompassed by our trial. Additionally, yearlings sustained a multitude of changes in diet, environment, and management throughout the study, yet ulcer scores never exceeded those observed at baseline. This may contradict the detrimental effects of reported risk factors. Since horses were given approximately $35 \mathrm{~d}$ to acclimate to 
each novel situation, it is also possible that adequate adjustment had occurred and the assumed stress was not detected as a manifestation of gastric ulcers by that time. There also was a trend for mean ulcer scores to be lower in Period 2 than Periods 1 or 3. During Period 2, ALF hay was fed with CB hay consumed in Periods 1 and 3. Although hay type cannot be separated from period, this data does corroborate previous data from this laboratory, which reported ALF hay to be anti-ulcergenic. When examining possible factors contributing to the decline of mean ulcer scores between baseline and the conclusion of Period 1, concentrate type surfaced as a possible factor in epithelial health and deserves further investigation. Additionally, the group feeding situation could have caused competition for feed through the establishment of social dominance, which was alleviated by feeding horses individually. This is another possibility that could be explored both on the excessive grain intake of a dominant individual or minimal concentrate intake and possibly a higher stress level in a submissive member of the herd. Furthermore, the yearlings on this study maintained adequate growth and did not exhibit skeletal deformities, even though the CON treatment group was marginally deficient in trace mineral intake of $\mathrm{Zn}, \mathrm{Mn}, \mathrm{Cu}$, and $\mathrm{Co}$, as compared to NRC recommendations.

Although there was no effect of trace mineral supplementation on gastric ulcer appearance and severity, avenues for future research were revealed by this study. Additional research is warranted into dietary alternatives, such as the specific components of ALF that appears to have an anti-ulcerogenic effect as compared to grass hay, as well as possible effects of a pelleted versus a textured concentrate. Furthermore, 
popular and accepted risk factors deserve further attention to determine the full magnitude of their effect on yearlings in training, a farm or university setting. Ultimately, elucidation of the pathogenesis of gastric ulcer formation by future research would help identify management options that could reduce the occurrence or severity of EGUS. 


\section{LITERATURE CITED}

Acda, S. P., and B. J. Chae. 2002. A review on the applications of organic trace minerals in pig nutrition. Pakistan J. Nut. 1 (1):25-30.

Alexander, S., and C. H. G. Irvine. 1998. Stress in the racing horse: coping vs not coping. J. Equine Sci. 9 (3):77-81.

Andrews, F. M., B. R. Buchanan, S. B. Elliot, N. A. Clariday, and L. H. Edwards. 2005. Gastric ulcers in horses. J. Anim. Sci. 83(E. Suppl):E18-E21.

Andrews, F. M., B. R. Buchanan, S. H. Smith, S. B. Elliott, and A. M. Saxton. 2006a. In vitro effects of hydrochloric acid and various concentrations of acetic, propionic, butyric, or valeric acids on bioelectrical properties of equine gastric squamous mucosa. Am. J. Vet. Res. 67:1873-1882.

Andrews, F. M., N. Frank, C. S. Sommardahl, B. R. Buchanan, S. B. Elliott, and V. A. Allen. 2006b. Effects of intravenously administrated omeprazole on gastric juice $\mathrm{pH}$ and gastric ulcer scores in adult horses. J. Vet. Intern. Med. 20:12021206.

Andrews, F. M., and J. A. Nadeau. 1999. Clinical syndromes of gastric ulceration in foals and mature horses. Equine Vet. J. 29 (Suppl):30-33.

Andrews, F. M., C. R. Reinemeyer, M. D. McCracken, J. T. Blackford, J. A. Nadeau, L. Saabye, M. Sotell, and A. Saxton. 2002. Comparison of endoscopic, necropsy, and histology scoring of equine gastric ulcers. Equine Vet. J. 34 (5):475-478.

Andrews, F. M., R. L. Sifferman, W. Bernard, F. E. Hughes, J. E. Holste, C. P. Daurio, R. Alva, and J. L. Cox. 1999. Efficacy of omeprazole paste in the treatment and prevention of gastric ulcers in horses. Equine Vet. J. 29 (Suppl):81-86.

Argenzio, R. A. 1999. Comparative pathophysiology of nonglandular ulcer disease: a review of experimental studies. Equine Vet. J. 29 (Suppl):19-23.

Argenzio, R. A., and J. Eisemann. 1996. Mechanisms of acid injury in porcine gastroesophageal mucosa. Am. J. Vet. Res. 57:564-573.

Amory, J. R., A. M. Mackenzie, G. P. Pearce. 2006. Factors in the housing environment of finisher pigs associated with the development of gastric ulcers. Vet. Rec. 158:260-264. 
Baker, L. A., T. Kearney-Moss, J. L. Pipkin, R. C. Bachman, J. T. Haliburton, and G. O. Veneklasen. 2003. The effect of supplemental inorganic and organic sources of copper and zinc on bone metabolism in exercised yearling geldings. Pages 100105 in Proc. $18^{\text {th }}$ Equine Nutr. Physiol. Symp., East Lancing, MI.

Baker, L. A., M. R. Wrigley, J. L. Pipkin, J. T. Haliburton, and R. C. Bachman. 2005. Digestibility and retention of inorganic and organic sources of copper and zinc in mature horses. Pages 162-167 in Proc. $19^{\text {th }}$ Equine Sci. Soc., Tuscon, AZ.

Begg, L. M., and C. B. O'Sullivan. 2003. The prevalence and distribution of gastric ulceration in 345 racehorses. Aust. Vet. J. 81:199-201.

Bell, R. J., J. K. Kingston, T. D. Mogg, and N. R. Perkins. 2007b. The prevalence of gastric ulceration in racehorses in New Zealand. New Zealand Vet. J. 55 (1):1318.

Bell, R. J., J. K. Kingston, and T. D. Mogg. 2007c. A comparison of two scoring systems for endoscopic grading of gastric ulceration in horses. New Zealand Vet. J. 55 (1):19-22.

Bell, R. J., T. D. Mogg, and J. K. Kingston. 2007a. Equine gastric ulcer syndrome in adult horses: a review. New Zealand Vet. J. 55 (1):1-12.

Berschneider, H. M., A. T. Blikslager, and M. C. Roberts. 1999. Role of duodenal reflux in nonglandular gatric ulcer disease of the mature horse. Equine Vet. J. 29 (Suppl):24-29.

Bertone, J. J. 2000. Prevalence of gastric ulcers in elite, heavy use western performance horses. Proc. Amer. Assoc. Equine Pract. 46:256-259.

Bezdekova, B., P. Jahn, and M. Vyskocil. 2007. Pathomorphological study on gastroduodenal ulceration in horses: localization of lesions. Acta Veterinaria Hungarica 55 (2):241-249.

Buchanan, B. R., and F. M. Andrews. 2003. Treatment and prevention of equine gastric ulcer syndrome. Vet. Clin. Equine 19:575-597.

Buff, C. E., D. W. Bollinger, M. R. Ellersieck, W. A. Brommelsiek, and T. L. Veum. 2005. Comparison of growth performance and zinc absorption, retention, and excretion in weanling pigs fed diets supplemented with zinc-poylsaccharide or zinc oxide. J. Anim. Sci. 83:2380-2386. 
Campbell-Thompson, M. L., and A. M. Merritt. 1987. Effect of ranitidine on gastric acid secretion in young male horses. Am. J. Vet. Res. 48 (10):1511-1515.

Cargile, J. L., J. A. Burrow, I. Kim, N. D. Cohen, and A. M. Merritt. 2004. Effect of dietary corn oil supplementation on equine gastric fluid acid, sodium, and prostaglandin $\mathrm{E}_{2}$ content before and during pentagastrin infusion. J. Vet. Inter. Med. 18:545-549.

Case, C. L., and M. S. Carlson. 2002. Effect of feeding organic and inorganic sources of additional zinc on growth performance and zinc balance in nursery pigs. J. Anim. Sci. 80:1917-1924.

Cohen, N. D. 2008. Personal Correspondence.

Collier, D. J. 1999. Gastric ulceration: response to an unnatural environment. Equine Vet. J. 9 (Suppl):5-6.

Collier, D. J., and S. J. Stoneham. 1997. Gastro-oesophageal ulcers in man and horse:semblance and dissemblance. Equine Vet. J. 29 (6):410-412.

Dial, S., J. A. C. Delaney, A. N. Barkun, S. Suissa. 2005. Use of gastric acidsuppressive agents and the risk of community-aquired Clostridium difficileassociated disease. J. Am. Med. Assoc. 294 (23):2989-2995.

Dieckgraefe, B. K., W. F. Stenson, D. H. Alpers. 1996. Gastrointestinal epithelial response to injury. Curr. Opin. Gastroenterol. 12:109-114.

Dionne, R. M., A. Vrins, M. Y. Doucet, and J. Pare. 2003. Gastric ulcers in standardbred racehorses: prevalence, lesion description, and risk factors. J. Vet. Intern. Med. 17:218-222.

Doucet, M. Y., A. A. Vrins, R. Dionne, R. Alva, and G. Ericsson. 2003. Efficacy of a paste formulation of omeprazole for the treatment of naturally occurring gastric ulcers in training standardbred racehorses in Canada. Can. Vet. J. 44:581-585.

Dukti, S. A., S. Perkins, J. Murphy, B. Barr, R. Boston, L. L. Southwood, and W. Bernard. 2006. Prevalence of gastric squamous ulceration in horses with abdominal pain. Equine Vet. J. 38 (4):347-349.

Dunlop, R. H., and C. H. Malbert. 2004. Pages 121-130 in Veterinary Pathophysiology. Blackwell Publishing, Ames, IA. 
Equine Gastric Ulcer Council (EGUC). 1999. Recommendations for the diagnosis and treatment of equine gastric ulcer syndrome (EGUS). Equine Vet. Educ. 11(5):262-272.

Eurell, J. C., B. L. Frappier, H. D. Dellman. 2006. Dellman's Textbook of Veterinary Histology. $6^{\text {th }}$ ed. Blackwell Publishing, Ames, IA.

Fellinus, E., T. Berglindh, G. Sachs, L. Olbe, B. Elander, S. E. Sjostrand, and B. Wallmark. 1981. Substituted benzimidazoles inhibit gastric acid secretion by blocking $\left(\mathrm{H}^{+}+\mathrm{K}^{+}\right)$ATPase. Nature 290:159-161.

Frank, N., F. M. Andrews, S. B., Elliott, J. Lew. 2005. Effects of dietary oils on the development of gastric ulcers in mares. Am. J. Vet. Res. 66:2006-2011.

Furr M. O., and M. J. Murray. 1989. Treatment of gastric ulcers in horses with histamine type-2 receptor antagonists. Equine Vet. J. 7 (Suppl): 77-79.

Furr, M. O., M. J. Murray, and D. C. Ferguson. 1992. The effects of stress on gastric ulceration, T3, T4, reverse T3 and cortisol in neonatal foals. Equine Vet. J. 24 (1):37-40.

Furr, M. O., L. Taylor, and D. Kronfeld. 1994. The effects of exercise training on serum gastrin response in the horse. Cornell Vet. 84:41-45.

Garey, S. M. 2009. Evaluation of stress before, during, and after transport in naïve yearling horses. A Thesis. Texas A\&M Univ., College Station

Hewetson, M., N. D. Cohen, S. Love, R. K., Buddington, W. Holmes, G. T. Innocent, and A. J. Roussel. 2006. Sucrose concentration in blood: a new method for assessment of gastric permeability in horses with gastric ulceration. J. Vet. Intern. Med. 20:388-394.

Holbrook, T. C., R. D. Simmons, M. E. Payton, and C. G. MacAllister. 2005. Effect of repeated oral administration of hypertonic electrolyte solution on equine gastric mucosa. Equine Vet. J. 37 (6):501-504.

Husted, L., L. C. Sanchez, S. N. Olsen, K. E. Baptiste, and A. M. Merritt. 2008. Effect of paddock vs. stall housing on 24 hour gastric $\mathrm{pH}$ within the proximal and ventral equine stomach. Equine Vet. J. 40 (4):337-341.

Jeffrey, S. C., M. J. Murray, and E. S. Eichorn. 2001. Distribution of epidermal growth factor receptor (EGFr) in normal and acute peptic-injured equine gastric squamous epithelium. Equine Vet. J. 33 (6):562-569. 
Ji, F., X. G. Luo, L. Lu, B. Liu, and S. X. Yu. 2006. Effect of manganese source on manganese absorption by the intestine of broilers. Poult. Sci. 85:1947-52.

Jonsson, H., and A. Egenvall. 2006. Prevalence of gastric ulceration in Swedish standardbreds in race training. Equine Vet. J. 38 (3):209-213.

LaCasha, P. A., ,H. A. Brady, V. G. Allen, C. R. Richardson, K. R. Pond. 1999. Voluntary intake, digestibility, and subsequent selection of Matua Bromegrass, Coastal Bermudagrass, and Alfalfa hays by yearling horses. J. Anim. Sci. 77:2766-2773.

Laheij, R. J. F., M. C. Van Ijzendoorn, M. J. R. Janssen, and J. B. M. J. Jansen. 2003. Gastric acid-suppressive therapy and community-acquired respiratory infections. Aliment. Pharmacol. Ther. 18:847-851.

le Jeune, S. S., J. E. Nieto, J. E. Dechant, and J. R. Snyder. 2008. Prevalence of gastric ulcers in Thoroughbred broodmares in pasture: a preliminary report. Vet. J. doi:10.1016/j.tvj1.2008.03.020

Lester, G. D., R. L. Smith, I. D. Robertson. 2005. Effects of treatment with omeprazole or ranitidine on gastric squamous ulceration in racing Thoroughbreds. J. Am. Vet. Med. Assoc. 227:1636-1639.

Lorenzo-Figueras, M., and A. M. Merritt. 2002. Effects of exercise on gastric volume and $\mathrm{pH}$ in the proximal portion of the stomach of horses. Am. J. Vet. Res. 63:1481-1487.

Lybbert, T. C. 2007. Gastric ulcer syndrome in exercising horses fed different types of hay. A Thesis. Texas A\&M Univ., College Station

MacAllister, C. G., F. M. Andrews, E. Deegan, W. Ruoff, and S. G. Olovson. 1997. A scoring system for gastric ulcers in the horse. Equine Vet. J. 29 (6):430-433.

MacAllister, C. G., and S. Sangiah. 1993. Effect of ranitidine on healing of experimentally induced gastric ulcers. Am. J. Vet. Res. 54 (7):1103-1107.

MacAllister, C. G., S. Sangiah, and A. Mauromoustakos. 1992. Effect of a histamine $\mathrm{H}_{2}$ type receptor antagonist (WY 45, 727) on the healing of gastric ulcers in ponies. J. Vet. Intern. Med. 6 (5):271-275.

McClure, S. R., D. S. Carithers, S. J. Gross, and M. J. Murray. 2005a. Gastric ulcer development in horses in a simulated show or training environment. J. Am. Vet. Med. Assoc. 227:775-777. 
McClure, S. R., L. T. Glickman, and N. W. Glickman. 1999. Prevalence of gastric ulcers in show horses. J. Am. Vet. Med. Assoc. 215:1130-1133.

McClure, S. R., G. W. White, R. L. Sifferman, W. Bernard, M. Y. Doucet, A. Vrins, J. E. Holste, C. Fleishman, R. Alva, and L. G. Cramer. 2005b. Efficacy of omeprazole paste for preventing of gastric ulcer in horses in race training. J. Am. Vet. Med. Assoc. 226:1681-1684.

McClure, S. R., G. W. White, R. L. Sifferman, W. Bernard, F. E. Hughes, J. E. Holste, C. Fleishman, R. Alva, and L. G. Cramer. 2005c. Efficacy of omeprazole paste for prevention of recurrence of gastric ulcers in horses in race training. J. Am. Vet. Med. Assoc. 226:1685-1688.

McDonald, P., R. A. Edwards, J. F. D Greenhalgh, and C. A. Morgan. 2002. Animal Nutrition. $6^{\text {th }}$ ed. Pearson Prentice Hall. Harlow, England.

Merritt, A. M. 2003. The equine stomach: a personal perspective (1963-2003). Proc. Am. Assoc. Equine Pract. 49:75-102.

Metayer, N., M. Lhote, A. Bahr, N. D. Cohen, I. Kim, A. J. Roussel, and V. Julliano. 2004. Meal size and starch content affect gastric emptying in horses. Equine Vet. J. 36 (5):436-440.

Miller, E. D., L. A. Baker, J. L. Pipkin, R. C. Bachman, J. T. Haliburton, and G. O. Veneklasen. 2003. The effect of supplemental inorganic and organic forms of copper and zinc on digestibility in yearling geldings in training. Pages 107-112 in Proc. $18^{\text {th }}$ Proc. Equine Nutr. Physiol. Sym., East Lancing, MI.

Mitchell, R. D. 2001. Prevalence of gastric ulcers in hunter/jumper and dressage horses evaluated for poor performance. Pages 1-3 Assoc. Equine Sports Med., Brunswich, NJ.

Monreal, L., D. Sabate, D. Segura, I. Mayos, and J. Homedes. 2004. Lower gastric ulcerogenic effect of suxibuzone compared to phenylbutazone when administered orally to horses. Res. Vet. Sci. 76:145-149.

Moore, R., S. Carlson, and J. L. Madara. 1989. Villus contraction aids repair of intestinal epithelium after injury. Am. J. Physiol. 257 (Gastrointest. Liver Physiol. 20):G274 - G283.

Murray, M. J. 1992. Gastric ulceration in horses: 91 cases (1987-1990). J. Am. Vet. Med. Assoc. 201 (1):117-120. 
Murray, M. J. 1994. Equine model of inducing ulceration in alimentary squamous epithelial mucosa. Dig. Dis. Sci. 39 (12):2530-2535.

Murray, M. J. 1999. Pathophysiology of peptic disorders in foals and horses: a review. Equine Vet. J. 29 (Suppl):14-18.

Murray M. J., and E. S. Eichorn. 1996. Effects of intermittent feed deprivation, intermittent feed deprivation with ranitidine administration, and stall confinement with ad libitum to hay on gastric ulceration in horses. Am. J. Vet. Res. 57:15991603.

Murray, M. J., E. S. Eichorn, and S. C. Jeffrey. 2001b. Histological characteristics of induced acute peptic injury in equine gastric squamous epithelium. Equine Vet. J. 33 (6):554-560.

Murray, M. J., C. Grodinsky, C. W. Anderson, P. F. Radue, G. R. Schmidt. 1989. Gastric ulcers in horses: a comparison of endoscopic findings in horses with and without clinical signs. Equine Vet. J. 77 (Suppl):68-72.

Murray, M. J., M. L. Haven, E. S. Eichorn, D. Zhang, J. Eagleson, and G. J. Hickey. 1997. Effects of omeprazole on healing of naturally-occuring gastric ulcers in Thoroughbred racehorses. Equine Vet. J. 29 (6):425-429.

Murray, M. J., Y. S. Nout, and D. L. Ward. 2001a. Endoscopic findings of the gastric antrum and pylorus in horses: 162 cases (1996-2000). J. Vet. Intern. Med. 15:401-6.

Murray, M. J., G. F. Schusser, F. S. Pipers, and S. J. Gross. 1996. Factors associated with gastric lesions in Thoroughbred racehorses. Equine Vet. J. 28 (5):368-374.

Nadeau, J. A., F. M. Andrews, A. G. Mathew, R. A. Argenzio, J. T. Blackford, M. Sohtell, and A. M. Saxton. 2000. Evaluation of diet as a cause of gastric ulcers in horses. Am. J. Vet. Res. 61:784-790.

Nadeau, J. A., F. M. Andrews, C. S. Patton, R. A. Argenzio, A. G. Mathew, and A. M. Saxton. 2003. Effects of hydrochloric, valeric, and other volatile fatty acids on pathogenesis of ulcers in the nonglandular portion of the stomach of horses. Am. J. Vet. Res. 64:413-417.

Naile, T. L., S. R. Cooper, D. W. Freeman, C. R. Krehbiel. 2005. Case Study: effects of mineral source on growth and balance in yearling horses. Prof. Anim. Sci. 21:121-127. 
Nieto, J. E., J. R. Snyder, P. Beldomenico, M. Aleman, J. W. Kerr, and S. J. Spier. 2004. Prevalence of gastric ulcers in endurance horses - a preliminary report. Vet. J. 167:33-37.

NRC, 1980. Mineral Tolerance of Domestic Animals. $1^{\text {st }}$ ed. Natl. Acad. Press, Washington, DC.

NRC. 2007. Nutrition Requirements of Horses. 6th rev. ed. Natl. Acad. Press, Washington, DC.

O’Connor, M. S., J. M. Steiner, A. J. Roussel, D. A. Williams, J. B. Meddings, F. Pipers, N. D. Cohen. 2004. Evaluation of urine sucrose concentration for detection of gastric ulcers in horses. Am. J. Vet. Res. 65:31-39.

Orlando, R. C. 2006. Esophageal mucosal defense mechanisms. NPG GI Motility Online doi:10.1038/gimo15 Accessed May 25, 2009.

Orsini, J. A., M. Haddock, L. Stine, E. K. Sullivan, T. S. Rabuffo, and G. Smith. 2003. Odds of moderate or severe gastric ulceration in racehorses receiving antiulcer medications. J. Am. Vet. Med. Assoc. 223:336-339.

Ott, E. A., and R. L. Asquith. 1989. The influence of mineral supplementation on growth and skeletal development of yearling horses. J. Anim. Sci. 67:28312840.

Ott, E. A., and R. L. Asquith. 1995. Trace mineral supplementation of yearling horses. J. Anim. Sci. 73:466-471.

Ott, E. A., and E. L. Johnson. 2001. Effect of trace mineral proteinates on growth and skeletal and hoof development in yearling horses. J. Equine Vet. Sci. 21:287291.

Rabuffo, T. S., J. A. Orsini, E. Sullivan, J. Engiles, T. Norman, and R. Boston. 2002. Associations between age or sex and prevalence of gastric ulceration in Standardbred racehorses in training. J. Am. Vet. Med. Assoc. 221:1156-1159.

Reese, R. E., and F. M. Andrews. 2009. Nutrition and dietary management of equine gastric ulcer syndrome. Vet. Clin. Equine 25:79-92.

Siciliano-Jones, J. L., M. T. Socha, D. J. Tomlinson, and J. M. DeFrain. 2008. Effect of trace mineral source on lactation performance, claw integrity, and fertility of dairy cattle. J. Dairy Sci. 91:1985-1995.

Stull, C. L. 1999. Response of horses to trailer design, duration, and floor area during commercial transportation to slaughter. J. Anim. Sci. 77:2925-2933. 
Vatistas, N. J., R. L. Sifferman, J. Holste, J. L. Cox, G. Pinalto, and K. T. Schultz. 1999b. Induction and maintenance of gastric ulceration in horses in simulated race training. Equine Vet. J. 29 (Suppl):40-44.

Vatistas, N. J., J. R. Snyder, G. Carlson, B. Johnson, R. M. Arthur, M. Thurmond, H. Zhou, and K. L. K. Lloyd. 1999a. Cross-sectional study of gastric ulcers of the squamous mucosa in Thoroughbred racehorses. Equine Vet. J. 29 (Suppl):34-39.

Vieira, S. L. 2008. Chelated minerals of poultry. Brazilian J. Poult. Sci. 10 (2):73-79.

Wagner, E. L., G. D. Potter, E. M. Eller, P. G. Gibbs, and D. M. Hood. 2005. Absorption and retention of trace minerals in adult horses. Prof. Anim. Sci. 21:207-211.

Wallace, J. L. 2001. Non-steroidal anti-inflammatory drugs and the gastrointestinal tract. Mechanisms of protection and healing: Current knowledge and future research. Am. J. Med. 110:19-23S.

Watanabe, T., T. Arakawa, T. Fukuda, K. Higuchi, and K. Kobayashi. 1995. Zinc deficiency delays gastric ulcer healing in rats. Dig. Dis. Sci. 40 (6):1340-1344.

White, G., S. R. McClure, R. Sifferman, J. E. Holste, C. Fleishman, M. J. Murray, and L. G. Cramer. 2007. Effects of short-term light to heavy exercise on gastric ulcer development in horses and efficacy of omeprazole paste in preventing gastric ulceration. J. Am. Vet. Med. Assoc. 230:1680-1682.

Widenhouse, T. V., G. D. Lester, and A. M. Merritt. 2002. Effect of hydrochloric acid, pepsin, or tauocholate on bioelectric properties of gastric squamous mucosa in horses. Am. J. Vet. Res. 63:744-749.

Wichert, B., K. Kreyenberg, and E. Kienzle. 2002. Serum response after oral supplementation of difference zinc compounds in horses. J. Nutr. 132:1769S1770 S.

Zinpro. 2004. Broilers fed zinc complexes show fewer intestinal lesions, better feed conversion. Tech Bull No. 7004. Zinpro Corporation, Eden Prairie, MN. 
APPENDIX 
Appendix 1A. Baseline data collection summary

\begin{tabular}{ccccc}
\hline \hline Horse ID & Treatment & Ulcer Score & BW $(\mathrm{kg})$ & BCS \\
\hline 63 & Control & 2 & 337.0 & 5.0 \\
66 & Control & 1 & 408.0 & 5.5 \\
53 & Control & 2 & 316.0 & 5.0 \\
58 & Control & 3 & 367.5 & 4.5 \\
72 & Control & 2 & 357.0 & 6.0 \\
57 & Control & 3 & 394.5 & 5.5 \\
59 & Control & 3 & 351.5 & 5.0 \\
710 & Inorganic & 3 & 345.5 & 5.5 \\
723 & Inorganic & 2 & 333.5 & 5.0 \\
726 & Inorganic & 1 & 392.5 & 5.5 \\
711 & Inorganic & 0 & 382.0 & 6.5 \\
705 & Inorganic & 2 & 332.5 & 6.0 \\
720 & Inorganic & 3 & 404.0 & 4.5 \\
618 & Organic & 0 & 364.5 & 4.5 \\
615 & Organic & 1 & 363.5 & 5.5 \\
200 & Organic & 2 & 395.5 & 5.5 \\
614 & Organic & 3 & 350.0 & 5.0 \\
310 & Organic & 3 & 395.5 & 5.5 \\
209 & Organic & 2 & 347.0 & 6.0 \\
612 & Organic & 3 & 430.5 & 5.0 \\
205 & Organic & 3 & 367.0 & 6.0 \\
\hline
\end{tabular}


Appendix 1B. Period 1 data collection summary

\begin{tabular}{ccccc}
\hline \hline Horse ID & Treatment & Ulcer Score & BW $(\mathrm{kg})$ & BCS \\
\hline 63 & Control & 2 & 347.0 & 4.0 \\
66 & Control & 2 & 431.5 & 6.0 \\
53 & Control & 2 & 334.5 & 4.5 \\
58 & Control & 2 & 380.0 & 4.0 \\
72 & Control & 1 & 368.5 & 5.0 \\
57 & Control & 2 & 407.5 & 5.5 \\
59 & Control & 2 & 363.5 & 4.0 \\
710 & Inorganic & 0 & 359.0 & 5.0 \\
723 & Inorganic & 2 & 345.0 & 5.5 \\
726 & Inorganic & 0 & 406.0 & 5.5 \\
711 & Inorganic & 2 & 388.0 & 6.5 \\
705 & Inorganic & 2 & 346.0 & 5.0 \\
720 & Inorganic & 2 & 421.5 & 4.5 \\
618 & Organic & 0 & 381.5 & 4.0 \\
615 & Organic & 2 & 373.5 & 5.5 \\
200 & Organic & 2 & 405.5 & 5.5 \\
614 & Organic & 0 & 350.5 & 5.0 \\
310 & Organic & 2 & 404.5 & 5.0 \\
209 & Organic & 0 & 364.0 & 5.5 \\
612 & Organic & 2 & 445.5 & 5.0 \\
205 & Organic & 2 & 378.0 & 6.5 \\
\hline
\end{tabular}


Appendix 1C. Period 2 data collection summary

\begin{tabular}{ccccc}
\hline Horse ID & Treatment & Ulcer Score & BW $(\mathrm{kg})$ & BCS \\
\hline 63 & Control & 2 & 361.0 & 5.5 \\
66 & Control & 0 & 462.0 & 6.0 \\
53 & Control & 2 & 342.5 & 5.5 \\
58 & Control & 1 & 394.5 & 4.5 \\
72 & Control & 2 & 383.0 & 6.5 \\
57 & Control & 2 & 438.5 & 6.0 \\
59 & Control & 0 & 391.0 & 5.5 \\
710 & Inorganic & 1 & 378.5 & 6.0 \\
723 & Inorganic & 2 & 364.0 & 6.5 \\
726 & Inorganic & 1 & 433.0 & 6.0 \\
711 & Inorganic & 0 & 408.0 & 7.0 \\
705 & Inorganic & 1 & 366.5 & 5.5 \\
720 & Inorganic & 2 & 433.5 & 5.0 \\
618 & Organic & 0 & 401.0 & 5.5 \\
615 & Organic & 2 & 395.5 & 6.0 \\
200 & Organic & 0 & 429.0 & 6.0 \\
614 & Organic & 0 & 372.5 & 5.0 \\
310 & Organic & 1 & 429.0 & 5.0 \\
209 & Organic & 0 & 376.0 & 6.0 \\
612 & Organic & 2 & 452.5 & 5.5 \\
205 & Organic & 0 & 410.5 & 6.5 \\
\hline
\end{tabular}


Appendix 1D. Period 3 data collection summary

\begin{tabular}{ccccc}
\hline \hline Horse ID & Treatment & Ulcer Score & BW $(\mathrm{kg})$ & BCS \\
\hline 63 & Control & 0 & 383.2 & 5.5 \\
66 & Control & 2 & 482.3 & 6.0 \\
53 & Control & 0 & 360.0 & 5.5 \\
58 & Control & 2 & 412.7 & 5.0 \\
72 & Control & 2 & 404.5 & 7.0 \\
57 & Control & 2 & 454.1 & 6.5 \\
59 & Control & 0 & 418.2 & 5.5 \\
710 & Inorganic & 1 & 401.8 & 6.0 \\
723 & Inorganic & 2 & 379.5 & 6.0 \\
726 & Inorganic & 2 & 450.5 & 6.0 \\
711 & Inorganic & 0 & 415.9 & 7.5 \\
310 & Inorganic & 2 & 437.3 & 6.0 \\
705 & Inorganic & 2 & 378.2 & 5.5 \\
720 & Inorganic & 2 & 463.2 & 5.5 \\
618 & Organic & 2 & 425.5 & 5.5 \\
615 & Organic & 2 & 411.8 & 6.5 \\
200 & Organic & 2 & 444.1 & 6.5 \\
614 & Organic & 2 & 379.1 & 6.0 \\
209 & Organic & 1 & 384.5 & 6.0 \\
612 & Organic & 2 & 476.4 & 5.5 \\
205 & Organic & 1 & 435.5 & 7.0 \\
\hline
\end{tabular}


Appendix 2A. Changes in ulcer score between periods

\begin{tabular}{cccccc}
\hline Horse ID & Treatment & $\begin{array}{c}\text { Baseline } \\
\text { Ulcer } \\
\text { Score }\end{array}$ & $\begin{array}{c}\text { Baseline } \\
\text { to } \\
\text { Period } 1\end{array}$ & $\begin{array}{c}\text { Period } 1 \\
\text { to } \\
\text { Period 2 }\end{array}$ & $\begin{array}{c}\text { Period 2 } \\
\text { to } \\
\text { Period 3 }\end{array}$ \\
\hline 63 & Control & 2 & 0 & 0 & -2 \\
66 & Control & 1 & 1 & -2 & 2 \\
53 & Control & 2 & 0 & 0 & -2 \\
58 & Control & 3 & -1 & -1 & 1 \\
72 & Control & 2 & -1 & 1 & 0 \\
57 & Control & 3 & -1 & 0 & 0 \\
59 & Control & 3 & -1 & -2 & 0 \\
710 & Inorganic & 3 & -3 & 1 & 0 \\
723 & Inorganic & 2 & 0 & 0 & 0 \\
726 & Inorganic & 1 & -1 & 1 & 1 \\
711 & Inorganic & 0 & 2 & -2 & 0 \\
310 & Inorganic & 3 & -1 & -1 & 1 \\
705 & Inorganic & 2 & 0 & -1 & 1 \\
720 & Inorganic & 3 & -1 & 0 & 0 \\
618 & Organic & 0 & 0 & 0 & 2 \\
615 & Organic & 1 & 1 & 0 & 0 \\
200 & Organic & 2 & 0 & -2 & 2 \\
614 & Organic & 3 & -3 & 0 & 2 \\
209 & Organic & 2 & -2 & 0 & 1 \\
612 & Organic & 3 & -1 & 0 & 0 \\
205 & Organic & 3 & -1 & -2 & 1 \\
\hline
\end{tabular}


Appendix 2B. Status of change in ulcer scores between periods in yearling horses fed no supplemental trace mineral, inorganic trace mineral, or organic trace mineral

\begin{tabular}{|c|c|c|c|c|c|c|c|c|c|}
\hline \multirow{3}{*}{ Item } & \multicolumn{9}{|c|}{ Period } \\
\hline & \multicolumn{3}{|c|}{1} & \multicolumn{3}{|c|}{2} & \multicolumn{3}{|c|}{3} \\
\hline & +1 & $0^{2}$ & $-^{3}$ & + & $\overline{0}$ & - & + & 0 & - \\
\hline \multicolumn{10}{|c|}{ Treatment } \\
\hline $\mathrm{CON}$ & 4 & 2 & 1 & 3 & 3 & 1 & 2 & 3 & 2 \\
\hline INO & 4 & 2 & 1 & 3 & 2 & 2 & 0 & 4 & 3 \\
\hline ORG & 4 & 2 & 1 & 2 & 5 & 0 & 0 & 2 & 5 \\
\hline Overall $^{4}$ & 12 & 6 & 3 & 8 & 10 & 3 & 2 & 9 & 10 \\
\hline
\end{tabular}

"“+" = improvement in ulcer score since the previous period.

2 " 0 " = no change in ulcer score relative to the previous period.

3،_“" = worse/more severe ulcer score than in previous period.

${ }^{4}$ Overall $=$ total number of horses displaying improvement, same, or worsening of ulcers across all treatment groups $(n=21)$ for each period $(n=3)$.

Appendix 3. Response to treatment ${ }^{1}$ of indicated variables.

\begin{tabular}{|c|c|c|c|c|c|}
\hline \multirow[b]{2}{*}{ Item } & \multicolumn{3}{|c|}{ Treatment } & \multirow[b]{2}{*}{ SEM } & \multirow[b]{2}{*}{$P$-value ${ }^{6}$} \\
\hline & $\mathrm{CON}^{2}$ & $\mathrm{INO}^{3}$ & $\mathrm{ORG}^{4}$ & & \\
\hline Ulcer Score & 1.6 & 1.5 & 1.4 & 0.20 & 0.60 \\
\hline Ulcer Score Change & -0.4 & -0.1 & -0.1 & 0.18 & 0.51 \\
\hline $\mathrm{BCS}$ & 5.4 & 5.7 & 5.6 & 0.20 & 0.48 \\
\hline Body Weight, kg & 387.6 & 396.8 & 392.7 & 12.61 & 0.87 \\
\hline $\mathrm{ADG}, \mathrm{kg}$ & 0.71 & 0.67 & 0.70 & 0.05 & 0.81 \\
\hline Total Weight Gain, kg & 59.9 & 56.4 & 58.4 & 1.38 & 0.83 \\
\hline DMI Grain, kg & 4.26 & 4.31 & 4.29 & 0.13 & 0.97 \\
\hline DMI Hay, kg & 3.22 & 3.20 & 3.19 & 0.09 & 0.99 \\
\hline Total DMI, kg & 7.48 & 7.51 & 7.48 & 0.22 & 0.99 \\
\hline ADI Supplement, g & $0.00^{\mathrm{a}}$ & $16.44^{\mathrm{b}}$ & $16.63^{\mathrm{b}}$ & 0.48 & $<0.0001$ \\
\hline
\end{tabular}

${ }^{\mathrm{a}, \mathrm{b}}$ Within a row, means without common superscripts are different $(P<0.0001)$.

${ }^{1}$ Least squares means were compared for indicated responses among treatment groups $(\mathrm{n}=3)$.

${ }^{2} \mathrm{CON}=$ treatment group with no trace mineral supplemented $(\mathrm{n}=7)$.

${ }^{3} \mathrm{INO}=$ treatment group supplemented with inorganic trace mineral $(\mathrm{n}=7)$.

${ }^{4} \mathrm{ORG}=$ treatment group supplemented with organic trace mineral $(\mathrm{n}=7)$.

${ }^{5}$ Least squares mean of the change in ulcer score among treatment groups.

${ }^{6} P$-value for overall treatment effect. 
Appendix 4. Response to period ${ }^{1}$ of indicated variables

\begin{tabular}{|c|c|c|c|c|c|c|}
\hline \multirow[b]{2}{*}{ Item } & \multicolumn{4}{|c|}{ Period } & \multirow[b]{2}{*}{ SEM } & \multirow[b]{2}{*}{ P-value ${ }^{3}$} \\
\hline & $0^{2}$ & $\overline{1}$ & $\overline{2}$ & 3 & & \\
\hline Ulcer Score & $2.1^{\mathrm{a}}$ & $1.5^{\mathrm{b}}$ & $1.0^{\mathrm{b}}$ & $1.5^{\mathrm{b}}$ & 0.20 & $<0.01$ \\
\hline Ulcer Score Change $^{4}$ & -- & $-0.62^{\mathrm{a}}$ & $-0.48^{\mathrm{a}}$ & $0.48^{\mathrm{b}}$ & 0.25 & $<0.01$ \\
\hline $\mathrm{BCS}$ & $5.4^{\mathrm{a}}$ & $5.1^{\mathrm{b}}$ & $5.8^{\mathrm{c}}$ & $6.0^{\mathrm{d}}$ & 0.14 & $<0.0001$ \\
\hline Body Weight, kg & $368.3^{\mathrm{a}}$ & $381.0^{\mathrm{b}}$ & $401.1^{\mathrm{c}}$ & $419.0^{\mathrm{d}}$ & 7.37 & $<0.0001$ \\
\hline ADG, $\mathrm{kg}$ & -- & $0.44^{\mathrm{a}}$ & $0.75^{\mathrm{b}}$ & $0.88^{\mathrm{c}}$ & 0.04 & $<0.0001$ \\
\hline Total Weight Gain, kg & -- & $12.7^{\mathrm{a}}$ & $20.5^{\mathrm{b}}$ & $25.0^{\mathrm{c}}$ & 1.26 & $<0.0001$ \\
\hline DMI Grain, kg & -- & $4.15^{\mathrm{a}}$ & $4.24^{\mathrm{b}}$ & $4.46^{\mathrm{c}}$ & 0.08 & $<0.0001$ \\
\hline DMI Hay, kg & -- & $3.12^{\mathrm{a}}$ & $3.35^{\mathrm{b}}$ & $3.15^{\mathrm{a}}$ & 0.06 & $<0.0001$ \\
\hline Total DMI, kg & -- & $7.27^{\mathrm{a}}$ & $7.59^{\mathrm{b}}$ & $7.61^{\mathrm{b}}$ & 0.13 & $<0.0001$ \\
\hline ADI Supplement ${ }^{5}, \mathrm{~g}$ & -- & $15.89^{\mathrm{a}}$ & $16.57^{\mathrm{b}}$ & $17.14^{\mathrm{c}}$ & 0.34 & $<0.0001$ \\
\hline
\end{tabular}

${ }_{\mathrm{a}, \mathrm{b}, \mathrm{c}, \mathrm{d}}$ Within a row, means without a common superscript are different $(P<0.05)$.

${ }^{1}$ Least squares means were compared for indicated responses among periods $(n=3)$.

${ }^{2}$ Measurements taken prior to initiating Period 1; blank cells are responses only calculated during an active period $(\mathrm{n}=3)$, there for having no baseline value.

${ }^{3} \mathrm{P}$-value for overall period effect.

${ }^{4}$ Least square means of change in ulcer score between two subsequent periods (Baseline to Period 1, Period 1 to Period 2, Period 2 to Period 3).

${ }^{5}$ Least squares means do not include control horses $(n=7)$, as they received no supplement. 
Appendix 5. The response ${ }^{1}$ of each indicated variable by treatment and period

\begin{tabular}{|c|c|c|c|c|c|c|c|c|c|c|c|c|c|c|}
\hline \multirow[b]{3}{*}{ Item } & \multicolumn{4}{|c|}{$\mathrm{CON}^{2}$} & \multicolumn{4}{|c|}{$\mathrm{INO}^{3}$} & \multicolumn{4}{|c|}{$\mathrm{ORG}^{4}$} & \multirow[b]{3}{*}{ SEM } & \multirow[b]{3}{*}{$\mathrm{TxP}^{5}$} \\
\hline & \multicolumn{4}{|c|}{ Period } & \multicolumn{4}{|c|}{ Period } & \multicolumn{4}{|c|}{ Period } & & \\
\hline & 0 & 1 & 2 & 3 & 0 & 1 & 2 & 3 & $\overline{0}$ & 1 & 2 & 3 & & \\
\hline Ulcer Score & 2.3 & 1.9 & 1.3 & 1.1 & 2.0 & 1.4 & 1.1 & 1.6 & 2.0 & 1.1 & 0.6 & 1.7 & 0.34 & 0.46 \\
\hline Ulcer Score Change & -- & -0.43 & -0.57 & -0.14 & -- & -0.57 & -0.29 & 0.42 & -- & -0.86 & -0.57 & 1.14 & 0.43 & 0.28 \\
\hline BCS & 5.2 & 4.7 & 5.6 & 5.9 & 5.5 & 5.3 & 5.9 & 6.1 & 5.4 & 5.3 & 5.8 & 6.1 & 0.24 & 0.38 \\
\hline $\mathrm{BW}, \mathrm{kg}$ & 361.6 & 376.1 & 396.07 & 416.4 & 369.4 & 381.4 & 401.8 & 418.1 & 374.0 & 385.5 & 405.3 & 422.4 & 12.76 & 0.88 \\
\hline $\mathrm{ADG}, \mathrm{kg}$ & -- & 0.51 & 0.79 & 0.85 & -- & 0.42 & 0.74 & 0.90 & -- & 0.40 & 0.71 & 0.89 & 0.08 & 0.85 \\
\hline Total Wt. Gain, kg & -- & 14.4 & 21.5 & 24.0 & -- & 12.1 & 20.6 & 25.7 & -- & 11.5 & 19.5 & 25.4 & 2.18 & 0.85 \\
\hline DMI Grain, $\mathrm{kg}$ & -- & 4.11 & 4.22 & 4.45 & -- & 4.20 & 4.27 & 4.45 & -- & 4.14 & 4.23 & 4.49 & 0.14 & 0.87 \\
\hline DMI Hay, kg & -- & 3.14 & 3.32 & 3.19 & -- & 3.16 & 3.33 & 3.14 & -- & 3.06 & 3.39 & 3.13 & 0.11 & 0.56 \\
\hline Total DMI, kg & -- & 7.25 & 7.54 & 7.64 & -- & 7.35 & 7.60 & 7.59 & -- & 7.20 & 7.62 & 7.62 & 0.23 & 0.61 \\
\hline ADI Suppl., g & -- & $0.00^{\mathrm{a}}$ & $0.00^{\mathrm{a}}$ & $0.00^{\mathrm{a}}$ & -- & $15.81^{\mathrm{b}}$ & $16.47^{\mathrm{c}}$ & $17.03^{\mathrm{d}}$ & -- & $15.95^{\mathrm{b}}$ & $16.67^{\mathrm{c}}$ & $17.25^{\mathrm{d}}$ & 0.40 & $<0.0001$ \\
\hline
\end{tabular}

$\overline{a, b, c, d}$ Within a row, means without a common superscript are different $(P<0.0001)$.

${ }^{1}$ Least squares means for the response variables by period and treatment group.

${ }^{2} \mathrm{CON}=$ control treatment group without trace mineral supplementation $(\mathrm{n}=7)$.

${ }^{3} \mathrm{INO}=$ treatment group supplemented with inorganic trace mineral $(\mathrm{n}=7)$.

${ }^{4} \mathrm{ORG}=$ treatment group supplemented with organic trace mineral $(\mathrm{n}=7)$.

${ }^{5} \mathrm{TxP}=P$-value for the interaction between treatment and period for the response variable in each row. 
Appendix 6. Hay refusal $5 \mathrm{~d}$ pre and post transportation in yearling horses

\begin{tabular}{lccccc}
\hline & \multicolumn{2}{c}{ Pre-transport } & & \multicolumn{2}{c}{ Post-transport } \\
\cline { 2 - 3 } \cline { 5 - 6 } Period & Horses $(\mathrm{n})$ & Avg Refusal & & Horses $(\mathrm{n})$ & Avg Refusal \\
\hline 1 & 13 & $0.24 \mathrm{~kg}$ & & 20 & $0.43 \mathrm{~kg}$ \\
2 & 5 & $0.26 \mathrm{~kg}$ & & 16 & $0.28 \mathrm{~kg}$ \\
3 & 15 & $0.47 \mathrm{~kg}$ & & 19 & $0.45 \mathrm{~kg}$ \\
\hline
\end{tabular}


VITA

Name: Alexa Dawn Hayes

Address: 240 Kleberg Center

2471 TAMU

College Station, TX 77843

Email Address: lexiehayes@gmail.com

Education: B.S., Animal Science and Industry, Kansas State University, 2007

M.S., Animal Science, Texas A\&M University, 2009

Experience: Graduate Teaching Assistant, Texas A\&M Department of Animal Science

- Introduction to Animal Science Lab, ANSC 108

- August 2007 - May 2009

- Equine Behavior \& Training Lab (A), ANSC 311

- August 2007 - May 2009

- Equestrian Technology, ANSC 312

○ June 2008 - August 2008

- Seminar, ANSC 481

- June 2009 - July 2009 